\title{
Looking for Earthquake Precursors From Space: A Critical Review
}

\author{
Piergiorgio Picozza ${ }^{1,2,3 *}$, Livio Conti ${ }^{2,3}$ and Alessandro Sotgiu ${ }^{1,2}$ \\ ${ }^{1}$ University of Rome Tor Vergata, Rome, Italy, ${ }^{2}$ INFN - Sezione Roma Tor Vergata, Rome, Italy, ${ }^{3}$ Uninettuno University, Rome, Italy
}

\section{OPEN ACCESS}

Edited by:

Dimitar Ouzounov,

Chapman University, United States

Reviewed by:

Angelo De Santis,

University of Studies G. d'Annunzio

Chieti and Pescara, Italy

Michel Parrot,

UMR7328 Laboratoire de physique et chimie de l'environnement et de l'Espace, France

${ }^{*}$ Correspondence:

Piergiorgio Picozza

Piergiorgio.Picozza@roma2.infn.it

Specialty section: This article was submitted to Geohazards and Georisks, a section of the journal Frontiers in Earth Science

Received: 08 March 2021 Accepted: 28 June 2021 Published: 14 July 2021

Citation:

Picozza P, Conti L and Sotgiu A (2021) Looking for Earthquake Precursors

From Space: A Critical Review.

Front. Earth Sci. 9:676775.

doi: 10.3389/feart.2021.676775
Starting from late seventies, many observations have been reported about observations in space of signals reconciled with earthquakes and claimed as possible preseismic measurements. The detected parameters range from electromagnetic field components (in a large band of frequencies) to plasmas parameters; from particles detection to thermal anomalies; etc. Up to the DEMETER mission, the analyses have been carried out on datasets gathered by not devoted satellites. Even beyond the results obtained, the DEMETER mission has constituted a milestone for space-based investigations of seismo-associated phenomena drawing a baseline for next missions with respect instruments, observational strategy and measurements uncertainty. Nowadays, the CSES-01 satellite - developed within a sino-italian collaboration with the participation also of Austrian Institutes - represents the most advanced mission for investigating near-Earth electromagnetic environment aimed at extending the observation of earthquake precursors to a long time series. The benefit of the mission is even higher by considering that CSES-01 is the first of a program of several LEO small satellites, the second of which will be launched on 2023 with the same instruments and orbit of CSES-01, but with a shift of half of an orbit in order to monitor each trace twice per orbit. The article gives a short survey of spacebased observations of preseismic phenomena from the early studies up to the more recent ones, critically reviewing results, hypotheses and trends in this research field. The supposed physical processes proposed to explain the observations are still unable to explain the large variety of the phenomenology, the statistical significance of the results are highly debated, and more in general a common consensus is still missing. Anyway, the investigation of the seismo-associated phenomena from space is a challenge for near future Earth observation.

Keywords: earthquake precursors, trapped particles, space weather, DEMETER, CSES, acoustic gravity waves, HEPD

\section{INTRODUCTION}

The key ingredient for studying the earthquake preparation process - and ideally for forecasting its occurrence - is to point out the existence of possible earthquake precursors (on long, middle, or short temporal scale) as well as their detection as a function of the distance (from the focal area of the impinging event). An extended review can be found for example in Tronin (2006), Hayakawa (2015), Pulinets and Ouzounov (2018), Parrot (2018), Ouzounov et al. (2018), Pulinets and Ouzounov (2018). Beyond the classification as a function of the time delay with respect the seismic event, precursors can be further distinguished on the spatial scale as a function of the detection distance and 
their localization or diffusion. In fact, some processes, candidate to be considered such as precursors, can be detected around the seismic focal area (local precursors) even though eventually at significant distance. Due to the topology of the geomagnetic field, other possible precursors can be detected not only over the epicentre, but also near to its magnetically conjugated region or along the field line with footprint on the epicentre (diffused precursors). Finally, a further class of precursors could be constituted by fluctuations detectable not only along a geomagnetic flux tube associated to the epicentre, but spread in suitable iono-magnetospheric "shell" (distributed precursors). Nowadays, earthquake forecasting is far from being reached and the debated about earthquake precursors is still open. Nevertheless, even though not conclusive results have been obtained, a large amount of measurements have been gathered worldwide with a large variety of methodology and the investigations of many different physical quantities and parameters, both on ground and in space. Unexpectedly, there is a problem of repeatability and confirmation of claimed results by different authors using the same methodology and/or analyzing the same parameters. Whereas the co-seismic effects in the atmosphere are well-established (Tanimoto et al., 2015), the possible pre-earthquake phenomena on the surface as well as the coupling between lithosphere, atmosphere and ionosphere (called LAIC for short, hereafter) are still disputed (e.g., Geller, 1997, Geller et al., 1997; Hough, 2020 and references therein). As it is very difficult to detail a debate (in which facts and views are sometimes mixed), we summarize only some of the main recent "trends" of discussion. A general skepticism about ground and space precursors (including thermal anomalies due to their "natural variability" and more in general for the "a posteriori" findings of the anomalies) is advocated by Jordan et al. (2011), Nakatani (2020) and - especially for seismic precursors - by Scholz (2019), although more recent results (e.g., Gulia and Wiemer, 2019) might change the perspective. Wang and Burgmann (2019) have questioned the reliability of precursory gravity changes; Helman (2020) has written in favor of the preseismic character of electrical signals, while Warden et al. (2020) support a critical view on ULF anomalies. Woith (2015) reviewed the "complexity" of investigating radon anomalies both as precursors to earthquakes and beyond this specific interpretation. In the debate on preseismic ionospheric anomalies, negative positions have been expressed by Dautermann et al. (2007), Thomas et al. (2012), Kamogawa and Kakinami (2013), Masci et al. (2015), Masci et al. (2017) and an analysis of the statistical reliability of some TEC anomalies can be found in Ikuta et al. (2020) and Tozzi et al. (2020). However, in a larger and reliable perspective, Kato and BenZion (2021) and Pritchard et al. (2020) have highlighted the potential of precursors. Uchida and Bürgmann (2021) have discussed the importance of short-term earthquake anomalies for more accurately establishing the seismic hazard of giant impending earthquake (although the same authors do not believe that such an event can be predicted with high confidence level). In this framework, this article presents a review of the main observations, hypotheses and models about the phenomenology of earthquake precursors observed in space, which, in our opinion, are valuable insights - that deserve to be investigated with the utmost precision and highest statistical accuracy - of the coupling mechanism existing between the lithosphere and the near-Earth environment (De Santis et al., 2015). For a review about the main earthquake precursors observed on ground (and further references about groundspace multi-parametric analyses) the interested reader is addressed to the twin article of Conti et al. (2021) in this same issue. The layout of the article is as follow. We will adopt a quasi-chronological approach discussing observations carried out in space before (section Seismo-Electromagnetic Perturbations Detected in Space by Non-Dedicated Missions) and after (section DEMETER Satellite Observations) the DEMETER mission that has been the first satellite devoted to investigate precursors from space. Then we will present the first results from the CSES satellite (section First Analyses From the CSES Satellite Mission) that is the first mission of a program including several satellites devoted to investigate seismo-induced phenomena in the near-Earth electromagnetic environment. Finally, in section Connecting Perturbations on Ground and in Space we will summarize some ideas about the physical mechanism for coupling lithosphere with lower and upper layers of the atmosphere up to the ionosphere.

\section{SEISMO-ELECTROMAGNETIC PERTURBATIONS DETECTED IN SPACE BY NON-DEDICATED MISSIONS}

Seismic events are the last stage of a long preparation process generated by a continuous and variable tectonic stress (Scholz, 2002; Olaiz et al., 2009). Many attempts have been done in order to monitor on ground the earthquake preparation phase and the underlying physical processes on specific fault systems (Kanamori, 2003), but the involved processes are deep, slow and complex. Since some tens of years, the possibility to remote sensing earthquakes though their effects in the nearEarth space has been explored. In order to explain the effects of the LAIC, Pulinets and Ouzounov (2011) proposed a model based on rising of gas and fluid toward the surface in the seismic preparation phase - that could take into account the last stages of the long-term seismic phase. Other hypotheses have been suggested by Sorokin et al. (2001), Hayakawa and Molchanov (2002), Liperovsky et al. (2008a), De Santis et al. (2017), De Santis et al. (2019a); etc. Freund (2011) proposed a mechanism, successfully tested in laboratory (Freund et al., 2007), based on the theory of positive holes that could locally ionize the lower atmosphere and create instability in the ionosphere. Finally Kuo et al. (2011), Kuo et al. (2014) proposed a coupling mechanism that, through the effect of the geomagnetic field of the Earth, would induce perturbation in the ionosphere.

\section{Early Observations of Electromagnetic Perturbations}

Several authors have reported measurements of seismoelectromagnetic precursors detected on ground or on board of 
satellite missions. After the early publications - mainly focused on analyzing electric and magnetic field variations - other studies have also discussed fluctuations of plasma parameters, precipitation of high-energy charged particles from the inner Van Allen belt, etc.

On 1982 were published the first observations of seismoelectromagnetic disturbances from space. Although some analyses of ionospheric disturbances that might occur before an earthquake - based on ground-based ionosonde data - were reported in the early 1970s [see e.g., Antselevich (1966); Datchenko et al. (1972)], the first results on satellite surveys of low-frequency electromagnetic emissions before earthquakes were obtained on data from the Intercosmos 19 satellite (Migulin et al., 1982; Gokhberg et al., 1983; Larkina et al., 1983); Aureol 3 mission (Larkina et al., 1984); while, the detection of VLF noise in the region magnetically conjugate to the earthquake zone was reported by Gokhberg et al. (1983) and Parrot et al. (1985) using observations from the geostationary satellites GEOS 1 and 2. Larkina et al. (1989) authored an analysis of Intercosmos 19 satellite data, detected at 800 and $4,650 \mathrm{~Hz}$, from about $8 \mathrm{~h}$ before up about $3 \mathrm{~h}$ after some earthquakes, within 2 degrees of latitude and 60 degrees of longitude around the epicentres. Chmyrev et al. (1989) reported an anomalous variation of $3-7 \mathrm{mV} / \mathrm{m}$ in the quasi $\mathrm{DC}$ component of the vertical electric field measured by the Intercosmos-Bulgaria 1300 satellite at the altitudes of about $800 \mathrm{~km}$ over the magnetically conjugate zone of the epicentre, about $15 \mathrm{~min}$ before an event of magnitude 4.8 in the Pacific Ocean.

Few years later, COSMOS-1809 detected anomalous electromagnetic emissions at frequencies below $450 \mathrm{~Hz}$, up to few hours before the seismic event, in more than $92 \%$ of the satellite traces, within 6 degree of longitude from the epicentre and about $4-10^{\circ}$ of latitude to the South of the Armenia earthquake of 1988 (Serebryakova et al., 1992). AUREOL-3 satellite data confirmed the observations, on the same region and events. By studying the seismic sequence of the Armenia earthquake of 1988, Kopytenko et al. (1993) and Serebryakova et al. (1992) reported some anomalous fluctuation of ULF magnetic and electric field measurements recorded on ground about $200 \mathrm{~km}$ far from the epicentre and some hours before the main event and some aftershocks.

Two years of AUREOL-3 satellite data, gathered in the ELF/ VLF frequency range, have been analyzed also by Parrot (1994) in the first statistical study published on space based observations of earthquake precursors. Through the superposed epoch and space method, applied to more than 300 seismic events of magnitude higher than 5, the analysis has pointing out a significant fluctuation of the electromagnetic field intensity within 10 degrees of longitude from the epicentres (of all latitudes), but without discriminating the temporal series of observations as pre, co- and post-seismic detections.

More recently, by re-analyzing data from IntercosmosBulgaria 1300 for hundreds earthquakes (Gousheva et al., 2008; Gousheva et al., 2009), estimated that the amplitude of preseismic quasi DC electric field disturbances in space was of the order of $10 \mathrm{mV} / \mathrm{m}$ over seismic events both in land and in sea.

\section{From Ground to Space: can be Radon the Root of the Coupling Mechanism?}

From space, several seismo-associated parameters can be measured such as lithospheric deformation, temperature fluctuation, gas and aerosol exhalation and electromagnetic field. While the co-seismic (horizontal and vertical) deformations can be significant (tens centimeters and meters) and can be monitored with InSAR with high precision and reliability (Moro et al., 2017; Zhao et al., 2018; Xu et al., 2020), the preseismic deformations are lower and more complex to be investigated from space (Tronin, 2006; Cenni et al., 2015; Moro et al., 2017; Nardò et al., 2020). Only in few cases, deformations have been detected both before and after seismic events (Massonnet et al., 1993; Kuzuoka and Mizuno, 2004; Tronin, 2006). Remote sensing observations allow also to measure concentrations of gases and aerosol in the atmosphere potentially involved in preseismic phenomena. Dey and Singh (2003) reported increase of surface latent heat flux before the Gujarat earthquake and some other coastal earthquakes. After the observations on ground of nighttime ionospheric fluorescence emissions by (Fishkova et al., 1985), that were correlated with physics of the E layer (85-110 km), Morozova (1996) reported an increase of the intensity of oxygen lines 5577 and $6300 \mathrm{~A}$ a few hours before seismic events.

One of the most debated issue in the physics of earthquake precursors includes the role of the seismo-induced radon exhalation in the generation of electromagnetic disturbances (Wakita et al., 1980; Teng et al., 1981; Cicerone et al., 2009). It has been proposed that the enhancement of total rock surface due to failure would increase the emissions of radon and other gases from grains and migration (Conti et al., 2021). This would be in agreement with: 1) the enhancement of radon concentration observed in aftershocks and 2) some laboratory experiments (Koike et al., 2015) aimed at verifying the growth of radon emissions of granites under compressional stress. Also in extensional tectonic regime, rock deformation can create cracks facilitating the radon and other gases exhalation (Reddy and Nagabhushanam, 2011) as demonstrated by Fu et al. (2017) by studying the variation of soil $\mathrm{Rn}$ concentration in shallow earthquakes $(<15 \mathrm{~km})$ in the extensional regime. Moreover, several authors have reported a temporal correlation between local variation of stress/strain and anomalous fluctuation of radon concentration in groundwater (Biagi et al., 2001; Ingebritsen and Manga 2014). It has been claimed that, due to radon exhalation from the soil, local fair-weather conductivity could increase up to 50\%, whereas the electric field could decrease of 30\% (Pierce, 1976). In this framework, Pulinets and Ouzounov (2011) and Pulinets et al. (2018) proposed a LAIC model that explains the synergy between earthquake activity and its precursors. According to this LAIC model, the relative movement of tectonic blocks leads to the generation of tectonic stresses with the release of gases (including radon) along seismically active faults. Radon can generate local ionization in the lower layers of the atmosphere that can facilitate water vapor condensation with: 1) release of latent heat exhalation (that could explain thermal fluctuations) and 
2) local variation of the conductivity that would impact on the global electric circuit over the earthquake preparation zone generating the observed seismo-associated ionospheric anomalies. Anyway, the radon exhalation seems cannot explain a direct generation of electromagnetic anomalies at higher frequency. We address the interested reader to the paper (Conti et al., 2021) published in this same issue, that provides a short review of models and ground based observations. In this framework, candidate precursor analyses have been performed on data from dedicated missions (DEMETER, CSES), multi-payload spacecraft (such as NOAA $14,15,16,17$, other Sun-synchronous LEO missions, weather and Earth observation satellites), Swarm satellites and for ionospheric sounding (as those of the FORMOSAT series). A summary of the main results will be given in the following sections.

\section{lonospheric Disturbances}

The large variety of atmospheric, ionospheric, and magnetospheric anomalies claimed as possibly being related to earthquakes shows the importance of both ground-based measurements of ionospheric parameters and satellite-based Earth remote sensing for investigating earthquake precursors (see Ondoh (2003); Ouzounov and Freund (2004); Pulinets and Boyarchuk (2005); Ondoh and Hayakawa (2006); Liu et al. (2006); Zhao et al. (2008); Ondoh, (2009); Kakinami et al. (2010); Perrone et al. (2010); Kandalyan and AlQuran (2010); Liou et al. (2010) and references therein). Anyway, it must be highlighted that many studies of seismo-ionospheric precursors are cases studies (seldom reproduces in further investigations carried out in "similar" conditions) and that many times the statistical significance is low. In general, the level of reliability changes significantly between the analyses and even in the scientific community involved in studying earthquake precursors the consensus is highly debated.

For the observations from ground of ionospheric preseismic phenomena, see Conti et al., 2021. For observations from space, in this section we just cite some of the earliest studies of plasma disturbances and observations from experiments different from DEMETER and CSES. Results from these latter missions will be discussed in the devoted DEMETER Satellite Observations and First Analyses From the CSES Satellite Mission.

Only few are the studies of plasma parameters detected by satellite in the early investigations of precursors. By analyzing data of IC-B 1300 satellite the authors of (Sorokin and Chmyrev, 1999) reported a dissipative instability of acoustic-gravity waves 15 min before an earthquake with $M=4.8$ and suggested that it would be due to an increased injection into the atmosphere of radioactive gas such as radon. Galperin et al. (1992) reported perturbations in electron profile and ion composition of the plasma, together with VLF anomalies, in a large extension of some degrees of longitude around the epicentral zone. Sharma et al. (2021) have analyzed 160 earthquakes in North East Indian region by studying GPS/TEC measurements, reporting TEC precursors in $46.5 \%$ of the $\mathrm{Mw}<5$ earthquakes, in more than $81.5 \%$ of $\mathrm{Mw}=5-6$ events and all the $\mathrm{Mw}>6$ earthquakes.

When several variables must be studied in order identify the "prevailing" ones and possible correlations, the principal component analysis (PCA) could be adopted for analyzing time series of observations and to reject background noise. After Hattori et al. (2004), that applied PCA to ground based observation of magnetic data, more recently, Zhu et al. (2019) applied PCA to Swarm satellite (Friis-Christensen et al., 2008) magnetic field data successfully finding seismo-related anomalies. Another recent examples of possible ionospheric electron density enhancement detected before large earthquakes $(M=7.0-8.0)$ have been reported by (He and Heki, 2017) by analyzing vertical total electron contents (VTEC) data observed by GNSS stations near the epicentres. In eight of the 32 earthquakes studied, possible preseismic anomalies were observed starting 10-20 min before the event. De Santis et al. (2019a) have analyzed 4.7 years of electron density ( $\mathrm{Ne}$ sampled at $2 \mathrm{~Hz}$ ) and magnetic field (mainly $\mathrm{Y}$ component at low frequency) data measured by Swarm three-satellite constellation (FriisChristensen et al., 2008). By using a worldwide statistical correlation analysis, through a superposed epoch approach, they have statistically studied the possible spatial and temporal correlation between the earthquakes and ionospheric disturbances. The authors reported a concentration of electron density and magnetic anomalies from more than two months up to some days before the seismic events with magnitude greater equal 5.5 and hypocentral depth up to $50 \mathrm{~km}$, studied in a time window from 90 days before up to 30 days after each event. A further interesting aspect of the performed analysis is that it would provide a confirmation based on space based measurements - from Swarm data, investigated in a time interval of 500 days before the seismic event - of the Rikitake empirical law for earthquake precursors (Rikitake, 1987), proposed in the earliest' 80 s for precursors on ground. The law, summarized by the formulas $\log _{10}(\Delta \mathrm{T})=a+b \mathrm{M}$ (where $\Delta \mathrm{T}$ is the precursor time, $\mathrm{M}$ is the earthquake magnitude and $a$ and $b$ are fit parameters) claims that the precursor time is a function of the earthquake magnitude: the larger the magnitude, the longer the precursor time. Interestingly, by analyzing ionospheric data ( $\mathrm{Ne}$ and $\mathrm{Y}$ magnetic component), the authors of (De Santis et al., 2019a) estimated values of the $a$ and $b$ parameters compatible with those proposed for ground magnetic observations by (Rikitake, 1987). The authors argue that the Rikitake law could take into account the LAIC. By assuming a lithospheric process of stress diffusion (Shapiro et al., 1997) across the Dobrovolsky strain radius (Dobrovolsky et al., 1979), the authors also obtained an estimation of the coefficient of diffusion too much higher than a reasonable value for the crust, but anyway of the same order of magnitude of the diffusivity found for slow earthquakes when a diffusion model is considered (Ide et al., 2007). Between the more recent analyses of ionospheric anomalies before strong earthquakes based on satellites observations we can cite also as significant examples Natarajan and Philipoff (2018), Zhang X. et al. (2019b), De Santis et al. (2020).

\section{Thermal Anomalies}

Several authors [see Tronin (2006), Conti et al. (2021) and references therein] have suggested that the earthquake preparation process can generate variation of temperature 
(induced by flow/exhalation of geochemical fluids in the deep lithosphere and/or by secondary effects of the friction and displacement along the seismic faults) that can affect the energy budget in the LAIC in seismic sequences (Qin et al., 2021). Only relatively few test campaigns have been carried out on ground and articles published about measurements of temperature variations before earthquakes that explains the small amount of this type of data and the large uncertainty on the subject (Cicerone et al., 2009). From one side, in volcanic areas, where also large earthquakes can take place, the temperature variations sometime observed before seismic events have been associated to groundwater level variations and gas releases, on the other side no anomalous temperature fluctuations have been detected for example in the investigations performed in the areas of the San Andreas fault. The most up-todate hypothesis for reconciling thermal fluctuations and seismic activity involves gas emissions due to the stress field in the earthquake preparation phase (e.g., Tramutoli et al., 2013). Preseismic processes could result in the release of radon and optically active gases (including carbon dioxide and methane) whose concentration could influence the thermal radiation emitted from the ground (Sorokin et al., 2005). In addition, the density ratio between released volatiles and air would influence the distribution pattern of thermal anomalies, which could be more concentrated for chemical species heavier than the air and more diffuse for lighter ones.

In the last years, the possibility to identify, on global scale, seismo-associated thermal anomalies has been enormously facilitated by continuous satellite monitoring. What is generically called thermal anomalies refer to anomalous fluctuations of several different parameters such as atmospheric temperature (at various altitudes), Brightness Temperature (BT), Surface Latent Heat Flux (SLHF), Outgoing Longwave Radiation (OLR), etc. For example, Qin et al. (2011) have found preseismic anomalies of SLHF (i.e., the heat released by phase changes that is function of several meteorological parameters including surface temperature, relative humidity, wind speed etc.) and Qin et al. (2012) reported surface temperature anomalies before two major earthquakes occurred in Emilia (Italy) on May 20, 2012, 2:03 UTC (ML 5.9) and on May 29, 2012, 7:00 UTC (ML 5.8). In this framework, Piscini et al. (2017) applied a multi-parametric analysis looking for anomalies in time series of climatological parameters (including skin temperature, total water vapor column, and total ozone column) and reported persistent anomalies during the Amatrice-Norcia seismic sequence (central Italy, 2016) that emerged simultaneously in all parameters analyzed.

In order to select seismo-associated TIR (Thermal InfraRed) anomalies with respect to not earthquake fluctuations due to natural and/or measurement failures, the RST (Robust Satellite Techniques) method has been proposed (Tramutoli, 1998; Bryant and Nathan, 2003; Tramutoli et al., 2005) aimed at distinguishing spatial and temporal outliers in long-term series of satellite observations. In this framework, the RETIRA (Robust Estimator of TIR Anomalies) index has been proposed (Filizzola et al., 2004; Tramutoli et al., 2005). RETIRA classifies the pixels of satellite images (not affected by cloudiness by means the OCA procedure (Cuomo et al., 2004) based on the number of standard deviations of the TIR brightness temperature with respect to the spatial and temporal mean value. By applying these approaches to several seismic sequences (with magnitudes between 4.0 and 7.9 occurred in different seismotectonic conditions) Tramutoli (2007) and Tramutoli et al. (2015) reported that TIR anomalies could be detected in a large areas (up to thousand square kilometers) around the epicenter from about one month before up to a few days after the earthquake. Even though RETIRA allows minimizing the fluctuations [due to natural features (such as topography and land cover); measurement method (including illumination and satellite view angle) and regular variations (i.e., daily, seasonal, and inter-annual cycle)] Martinelli et al. (2020) highlighted that the procedure is intrinsically not protected by the proliferation of signal outliers. Weiyu et al. (2018) have studied air temperature variations in multiple layers before, during and after the Jiujiang (China) earthquake [of magnitude 5.7 occurred at 00:49 (UTC) on November 26, 2005], and reported some pre-seismic increase of temperature in the atmosphere before earthquake, with heat flow propagating from ground to higher altitude where finally dissipates. Finally, several authors reported that - because remote sensing of thermal infrared anomalies is clearly affected by cloud coverage (Blackett et al., 2011) - it is hard to discriminate thermal contribution emitted by ground possibly connected to seismic activity in cloudy conditions [see for example Zhang and Meng (2019) for the study in the Sichuan area]. Thermal anomalies and related multi-instrumental observations will be furtherly discussed also in Remote Sensing and Multi-Parametric Approach.

\section{Acoustic Gravity Waves}

Between the several hypotheses proposed to reconcile the observed anomalies on ground and in space with seismic activity, it has been proposed that acoustic (AW) and acoustic gravity waves (AGW) could be responsible of the coupling between lithospheric processes and tropo-ionospheric disturbances (Korepanov et al., 2009). Molchanov and Hayakawa (1998) and (Molchanov et al., 2001) suggested that the variation of the morning/evening terminator times - observed in the plots of amplitude and phase of the ground-based VLF measurements in Japan, before the Kobe earthquake on 1995 could be induced by lithospheric oscillations through the occurrence of planetary waves with periods from few up to 10 days. Theses authors suggested that the modulation of VLF terminator time as well as the reduction of the amplitude and the enhanced dispersion of VLF intensity (observed during nightime, a few days before seismic events, in a statistical analysis including 7 years of earthquakes in the Japan area) could be induced by a decrease of a few $\mathrm{km}$ in the VLF reflection height possibly caused by AGW. It is interesting to notice that this effect is confirmed by Němec et al. (2009) and Píša et al. (2013) (see the following Electromagnetic Field Anomalies) that show a decrease of the wave intensity of electric field measured by ICE on board of DEMETER (more intense when the magnitude is larger) in a frequency range close to $1.7 \mathrm{kHz}$. If the intensity of the electric field decreases, it means that the cut-off frequency is increasing 
and then, it means that the height of the ionosphere is statistically lower above epicenter. Therefore, it is particularly relevant that all these studies (Molchanov and Hayakawa, 1998; Molchanov et al., 2001; Němec et al., 2009; Píša et al., 2013) based on two very different experiments, support the common idea that at the bottom of the ionosphere, above epicentre of impending earthquake, there is a statistically relevant excess of ionization. Changes of ground motion and/or temperature and pressure would induce oscillations in the atmosphere over the earthquake preparation zone that can propagate up to the ionosphere (Molchanov et al., 2001; Miyaki et al., 2002; Korepanov et al., 2009; Muto et al., 2009; Hayakawa et al., 2011). Through a wavelet analysis, Nakamura et al. (2013) showed that the fluctuations in the period of $10-100 \mathrm{~min}$ (which is in the range of AGW) were enhanced before the Niigata-Chuetsu earthquake $(M=6.8)$ of 2004. Endo et al. (2013) extended the study to AW and AGW (with a period of 1-10 $\mathrm{min}$ ) rising the conclusion that before two earthquakes (Niigata-Chuetsu Oki $(\mathrm{M}=6.8) 2007$, and Iwate-Miyagi $(\mathrm{M}=$ 7.2) 2008) the oscillations would have been enhanced when the lower ionosphere was perturbed. Based on GPS measurements, Kamiyama et al. (2016) claimed a temporal correlation between seismic crustal oscillations before the 2011 Tohoku (M 9.0) earthquake and ULF magnetic and VLF/LF ionospheric disturbances observed for this earthquake by several authors (Maekawa et al., 2006; Hayakawa et al., 2012; Hayakawa et al., 2013a, 2013b; Ohta et al., 2013; Schekotov et al., 2013). Phanikumar et al. (2018) suggested that earthquake precursors could involve not only charged ionospheric components but also neutral atmospheric species. In fact, the authors pointed out an anomalous and simultaneous fluctuation at mesospheric altitude - corresponding to the VLF reflection height - of the ozone density (measured by the TIMED satellite of the NASA's Solar Terrestrial Probes program) together with VLF signals detected on ground, before two earthquakes of 7.8 and 7.3 magnitude occurred on 2015 near Gorkha (Nepal). The hypothesis of a correlation between preseismic processes, tropoionospheric oscillations and thermal fluctuation has been supported also by the studies of Chakraborty et al. (2018). Starting from 3 to 4 days before the M7.3 earthquake of Gorkha (Nepal), the authors have found three correlated phenomena: 1) an anomalous fluctuation of the OLR satellite data (that can be related to thermal anomalies); 2) the occurrence of AGW of period of about $1 \mathrm{~h}$ and 3) groundbased detection of VLF disturbances. More recently the correlation between the occurrence of $\mathrm{AW} / \mathrm{AGW}$ and the observation of TEC, plasma and VLF disturbances has been reported by several authors (such as for example Rozhnoi et al., 2013; Hayakawa et al., 2018; Piersanti et al., 2020) and further support to the AGW hypothesis has been provided by Yang et al. (2019) and Lizunov et al. (2020). On the other side, it has been argued that, as the geo-chemical and the electromagnetic hypotheses, also that of the preseismic occurrence of AW/AGW is not able to explain all the phenomenology of the LAIC process, since the observations are not conclusive in supporting/excluding any of the proposed models (Pulinets and Boyarchuk,
2005; Liperovsky et al., 2008b; Oyama et al., 2016). It can be believed that different mechanisms could coexist and contribute together in different conditions on several spatial/temporal scales.

\section{Electromagnetic Field Measurements}

Zhang et al. (2012) have analyzed two series of electric field measurements before the Wenchuan earthquake of May 12, 2008, M8.0: a long time series (since March 2008) detected on ground, and a shorter series (1-2 days) measured by ICE on board of DEMETER satellite. The time occurrence and spatial distribution of ground- and space-based measurements are consistent between them for long and short time series. The authors have found that the amplitude of measured electric field anomalies (detected a few days before the earthquake was: from about $3 \mathrm{mV} /$ $\mathrm{km}$ up to $100 \mathrm{mV} / \mathrm{km}$ (on ground) and of about $3-5 \mathrm{mV} / \mathrm{m}$ at frequencies $<0.5 \mathrm{~Hz}$ (relative variation $>4 \%$ ) (for space data). The amplitudes differ largely between ground and satellite observations, so that it is difficult to reconcile ground and space-based measurements via a direct propagation of electromagnetic waves from the lithosphere through the atmosphere up to the ionosphere. Bortnik and Bleier (2004) and Bortnik et al. (2010) have shown that seismoelectromagnetic signals generated in the lithosphere at frequencies $<20 \mathrm{~Hz}$ could be able to cross the ionosphere, with the most severe attenuation occurring in the propagation under the ground and in the D-region. For frequencies in the range of $0.1-1 \mathrm{~Hz}$, the attenuation of the signals seems to be moderate (about $0.01 \%$ ), which means that if such signals are generated by earthquakes at the assumed location (depth of about $10 \mathrm{~km}$ ), these signals should contain sufficient power to be detected aboard satellite. Bortnik and Bleier (2004) suggested an electromagnetic signal in the focal depth of the order of $300.000 \mathrm{mV} / \mathrm{km}$, but this is much higher than the $3-100 \mathrm{mV} /$ $\mathrm{km}$ observed in the three ground stations before the Wenchuan earthquake. The anomalous electric field measured on ground are often from a few tens $\mathrm{mV} / \mathrm{km}$ up to a few hundred $\mathrm{mV} / \mathrm{km}$ (Xiong, 1992). It means that the amplitude of ground observed electromagnetic emissions would be still far lower than that detected in space: amplitudes detected by ICE were of about $3 \mathrm{mV} / \mathrm{m}$. Consequently a "simple" wave propagation cannot explain the observed phenomenology.

By considering the exponential damping of the electromagnetic spectrum intensity vs. frequency, several authors (such as Hayakawa et al., 1999; Smirnova et al., 2001; Molchanov et al., 2004; Hobara and Parrot, 2005; Hayakawa et al., 2009; Imamura et al., 2010) have shown that (for ground and space-based observations) the electric field spectrum (SE) before strong earthquakes has a typical fractal feature: $\mathrm{SE}=a \times \mathrm{f}^{b}$ (with $a$ and $b$ fit parameters). Zhang et al. (2010) have pointed out that the electric field Intensity detected by ICE in the Chile area before several earthquakes would show the same dependency from the frequency. The authors have analyzed ICE data in the frequency range $19.5-250 \mathrm{~Hz}$ and earthquakes near the Chile area, with $\mathrm{M}$ $>6.0$, from 2004 to 2010, in nighttime, in a time window of 5 days around the earthquakes. The study has pointed out that in two thirds of the earthquakes in this region, ULF/ELF electric field 
perturbations have been detected and that $\mathrm{Ne}, \mathrm{dNe} / \mathrm{Ne}, \mathrm{Te}, \mathrm{dTe} /$ Te have always varied simultaneously with ELF electromagnetic fluctuations. More recently, by studying two months of Swarm magnetic data around the M 7.8 Nepal earthquake (April 25, 2015, 06:26 UTC), De Santis et al. (2017) reported that the cumulative number of magnetic anomalies (measured nighttime, in geomagnetically quiet conditions) shows a power-law behavior typical of a critical system (with the approach to the critical time and the recovery phase). Based on the similarity of this behavior with that of seismic data, the authors suggest that the LAIC has generated the reported anomalies during the preparation phase of Nepal earthquake.

\section{Particle Precipitations From the Van Allen Belts}

In the Earth magnetosphere, the magnetic field is able to trap charged particles (electron, positrons, protons and ions) up to energies of tens or hundreds of $\mathrm{MeV}$ generating the so-called inner and outer radiation belts separated by the slot region originated by particle flux depletion due to interactions with whistler waves. The inner Van Allen belt is mainly constituted by protons and electrons through the decay of albedo neutrons (Zhang K. et al., 2019) originated by cosmic rays impinging the upper atmosphere (CRAND process). Electrons are the main constituent of the outer belts eventually energized through waveparticle interactions. Whistlers are the main source of particles precipitation via the so-called whistler electron precipitation (WEP) (Dungey, 1963; Rodger et al., 2003) due to the resonant interaction between circularly polarized VLF $(3-30 \mathrm{kHz})$ waves traveling along the geomagnetic field lines and trapped electrons resulting in their deflection in the loss cone and the consequent precipitation. The Sun is the main driver of the magnetospheric particles dynamics, but precipitation can be induced also by nuclear explosions (that can originated also long-term trapped artificial belt); by the already cited VLF emissions generated by lightning; by artificial radio signals (Sauvaud et al., 2008) and possibly by electromagnetic emission due to seismic activity. Such precipitations of electrons and protons can be observed by satellite detectors as sudden increases of the particles fluxes on the scale from few up to tens of seconds. It has been suggested that, the stable motion of high-energy trapped and quasi-trapped Van Allen particles can be perturbed also by seismo-associated electromagnetic emissions (Aleshina et al., 1992; Galperin et al., 1992). These authors suggested that electromagnetic emissions eventually generated in the preparation phase of an earthquake could modify the particles pitch angle, inducing the lowering of their mirror points and finally causing particles precipitation that are detected as sudden particles flux increase with LEO detectors. During precipitation, such burst of particles could still follow partially their longitudinal drift, that would increase the satellite capability of their detection in space not only over the hypocentral zones, but also even far from the area of the preparation earthquake. Russian scientists carried out the earliest analyses of these correlations with measurements of: MARIA detector installed on the SALYUT-7 station (Chesnokov et al., 1987; Voronov,
1990), MARIA-2 experiment on board MIR; ELECTRON experiments carried out on the INTERCOSMOS-BULGARIA1300 and METEOR-3 satellites (Galper et al., 1989); GAMMA detector, etc. At the beginning of this century, Aleksandrin et al. (2003) and Sgrigna et al. (2005b) have published careful analyses of such phenomenon on data collected by the PET experiment on board the SAMPEX NASA satellite, obtaining a statistically reliable temporal correlation between seismic events and charged particle precipitation from the lower boundary of the inner Van Allen radiation belt. Particle Burst (PB) are defined such as anomalous increases of the count rates beyond the background fluctuation. By studying the distribution of the time difference between earthquakes and anomalous particle detections, $\pm 36 \mathrm{~h}$ around the earthquake time, the authors of Aleksandrin et al. (2003) and Sgrigna et al. (2005b) have observed a peak at about $4-5 \mathrm{~h}$ with a significance of 5 sigma out of the mean, showing that the burst precipitation would occur before the earthquakes. This result was obtained using data driven algorithms - independent from specific LAIC model - and by considering together the all SAMPEX database. The result provides a good evidence (with a high statistical significance) of particle precipitation induced by seismic activity. Fidani and Battiston (2008) and Battiston and Vitale (2013) have extended the study on a larger time period with a different methods for background rejections. The authors have investigated the correlations between precipitation of low energy electrons ( $\mathrm{E}>$ $0.3 \mathrm{MeV}$ ) from the NOAA satellites (POES 15, 16, 17 and 18) and about 18,000 earthquakes of magnitude greater than 5 (from USGS) along 13 years. The distribution of time differences between earthquakes and detected particle bursts is uniform (mean $=8.3, \mathrm{SD}=2.9$ ) within the statistical errors, but the authors observe a large excess at $-1.25 \pm 0.25 \mathrm{~h}$ (i.e., after the earthquakes time). The temporal correlation, i.e., the possibility to measure anomalous particle burst with space based detectors before/after the seismic events, depends on the particles longitudinal drift period (around the Earth). For electrons of $300 \mathrm{KeV}$ the drift period is of about $4 \mathrm{~h}$, that allowed the authors to conclude that the observed peak is anyway due to a preseismic phenomenon detected by the satellite after the earthquake occurrences. The statistical significance of the found correlation peak is of 5.7 sigma, corresponding to a probability of $1.2 \times 10^{-6}$ of being a statistical fluctuation. Further studies are in progress (Fidani, 2018) in order to reconstruct the spatial area of the wave-particle interaction (that has induced the precipitation events) based on the detection point and features of the precipitating particles. By studying the distribution of earthquakes with magnitude $M>5$, as a function of the McIlwain L-shell and time, the research group of the AGILE satellite found an enhancement of particle bursts detected by the AGILE satellite, with a significance of 4 sigma, during the period August 5-September 3, 2007 (De Santis et al., 2015). The particle flux increase was in apparent coincidence with the earthquake shower in Peru that started with the $M=8$ event on August 15, 2007 (Ica event). In general, even though several authors have published reports of correlations between seismic events and anomalous particles precipitation - that would precede of few hours the occurrence of earthquake of moderate and strong 
magnitude - the phenomenon is still asking for a large and wellassessed statistical confirmation that is one of the purposes of the experiments carried out on the CSES satellite, the most advanced satellite devoted to investigate precursors phenomena from space.

\section{Remote Sensing and Multi-Parametric Approach}

The investigation of earthquake precursors from space not only shows the advantage of worldwide coverage of seismic areas, but also offers the possibility of exploiting new methods. Remote sensing makes it possible to monitor multiple parameters for precursor signatures in the simultaneous variation of several physical variables (above the epicenter, around it and in its conjugate zone), but also to survey large areas that could be affected by the earthquake preparation process but cannot be monitored with the network of scattered ground stations (see for example Hayakawa, 2009; Ouzounov et al., 2018; De Santis et al., 2019b). In this framework, Pulinets et al. (2006) have highlighted that because the peak of preseismic radon exhalation would occur 4-10 days before the earthquake, the time scale of radon variations and that of the observed air temperature variations are comparable (Inan et al., 2008) that is compatible with their multi-parametric analysis of the anomalies of surface temperature, latent heat flux, air temperature and relative humidity observed before the Colima (Mexico) earthquake (M7.6) of 2003; the M7.1 Hector Mine (United States) event of 1999 and the Parkfield (United States) earthquake (M6) of 2004 .

The potential of a multi-parameter statistical analysis of satellite data was highlighted by the joint study, published by De Santis et al. (2019c), on electron density and magnetic field measured during 2.5 years by the Swarm satellite (with quiet geomagnetic conditions) in a time window of one-month before and after 12 strong earthquakes. The authors report that the detected anomalies (limited to the Dobrovolsky area, statistically defined and normalized with respect to the number of satellite background tracks) show a linear dependence on the earthquake magnitude, which may support the hypothesis of their seismic origin and exclude a random correlation.

Between the multi-parametric analyses, several studies have been devoted the outgoing long-wave radiation (OLR). OLR is the flux of thermal radiation (between about 4 and $100 \mu \mathrm{m}$ ) emitted from the Earth to space and is measured by satellites such as NOAA14, 15, 16 and 17. In the global system of heating/cooling of the Earth, OLR is the main way in which the planet loses energy and includes the integrated effect of atmospheric species, cloud formation, aerosol balance, ocean whitecap, albedo, emissions from land and sea surfaces, etc. There are several advantages of investigating earthquake precursors through OLR because the data are available worldwide and OLR takes into account the (large spatially integrated) contributions of all soil-atmosphere coupling processes, including direct and indirect effects of earthquakes (such as radon release, ionization, latent heat release, etc.) that may occur over large areas around the epicenter, but that would be difficult to monitor with a network of local stations. Ouzounov et al. (2007) studied the OLR anomaly of the eddy field with respect to reference values averaged over months and years (in the period 1999-2004) before and after several seismic events, at different spatial resolutions $\left[1^{\circ} \times 1^{\circ}\right.$ and $2.5^{\circ} \times 2.5^{\circ}$ in latitude and longitude. The eddy field is defined as the sum of the differences of the OLR measured value between adjacent points in the analyzed period (day/month) (Liu et al., 1999; Liu, 2000; Kang and Liu, 2001). Ouzounov et al. (2007) report transient OLR anomalies (in the range 10 and $13 \mu \mathrm{m})$ before several strong events: $\Delta$ OLR $\sim+6 \mathrm{~W} / \mathrm{m}^{2}, 5$ days before the Bhuj (India) earthquake of M7.9, January 26, 2001); $\Delta$ OLR $\sim+10 \mathrm{~W} / \mathrm{m}^{2}$, the month before the M6.8 event in Boumerdes, (Algeria), May 21, 2003; several anomalous OLR increases in the months before the M6.6 Iran earthquake, December 26, 2003 (with the largest $\Delta$ OLR of $+22 \mathrm{~W} / \mathrm{m}^{2}$, occurring about two weeks before the event); several OLR anomalies before the M9.0 Sumatra earthquake, December 26, 2004 (including the largest one of $+80 \mathrm{~W} / \mathrm{m}^{2}$, on 21 December). Above the epicenter of the Sumatra event, Ouzounov et al. (2005) also reported anomalies of surface latent heat flux and GPS/TEC, also about 5 days before the earthquake. Based on the joint observation of several variations of thermal, atmospheric and ionospheric parameters, Ouzounov et al. (2007) suggested that the observed pre-earthquake OLR anomalies could be explained by the chain of phenomena of LAIC model triggered by the radon release (Pulinets and Boyarchuk, 2005; Pulinets et al., 2006; Pulinets and Ouzounov, 2011). Starting from the Ouzounov et al. (2007) seminal work, OLR anomalies have been observed for many other seismic events, such as for example before (from 19 to December 24, 2009) the M7.0 Haiti earthquake of January 12, 2010 (Xiong et al., 2010); before the M7.7 Awaran (Pakistan) earthquake of September 24, 2013 (Venkatanathan and Natyaganov, 2014); before the M7.0 Jiuzhaigou (China) earthquake, August 8, 2017 and the M 7.1 Mexico earthquake occurred on September 20, 2017 (Zhai et al., 2020). Fu et al. (2020) have recently applied the analysis of OLR data for studying ten years (2009-2019) of earthquakes in the Taiwan area. With an epoch-superimposed method, the authors have found consecutive anomalies before strong events $(M \geq 6.0)$. Particularly interesting is the advance time of the temporal profile of daily OLR anomalies index (analyzed in a timewindow of 25 days before and after the earthquake, see Figure 4 of $\mathrm{Fu}$ et al. (2020) that shows a peak 2-15 days before the events regardless of being in the daytime or the nighttime. The authors claim that, after removing the background due to typhoon's occurrence, OLR anomalies have been observed before about $77 \%$ of the earthquakes while weak seems the correlation between the number of OLR anomalies index and the earthquake's magnitude (apparently, the increasing intensity of OLR anomalies would not be associated with increased magnitude). An important multi-parametric analysis of atmospheric and ionospheric data collected on ground and from space (OLR, GPS/TEC, LEO ionospheric tomography and critical frequency foF2) has been carried out for the M9 Tohoku (Japan) earthquake of March 11, 2011 (Ouzounov et al., 2011). The authors report a chain of anomalies in the days before the 
earthquake: an OLR anomalies near the epicenter (on March 7th), an anomalous increase of electron density (GPS/TEC data, from March 8th), and a large increase in electron concentration detected in all 4 Japanese ground-based ionosondes (from March 3 to 11), which returned to normal a few days after the main shock of March 11. Some of the recorded TEC anomalies occurred between two minor/moderate geomagnetic storms, while the major increase (on March 8) was measured during a geomagnetically quiet period. Based on the long duration of the detected disturbances over the Sendai region, the authors excludes a meteorological or geomagnetic activity origin and suggested a preseismic character of the observed phenomenology.

De Santis et al. (2020) carried out an analysis, paradigmatic of the multi-parametric approach - by correlating ground and space-based data of seismicity, atmospheric temperature, water vapor, aerosol, methane, ionosonde measurements as well as electron density and magnetic field observations from Swarm satellite - studying the seismic sequence of Ridgecrest (CA, United States) 2019, started on July 4 and culminating with the M7.1 event of 6 July (that included also several large foreshocks of M6.4, M5 and M5.4). The results suggested a chain of multiple precursor anomalies during a preparation phase (September 2018 to July 2019) much longer than that identified by many other works, particularly on ionospheric precursors, which appeared to be limited to only a few hours to days before large earthquakes (e.g., Heki, 2011; He and Heki, 2017; Yan et al., 2017). The same long preparation phase is confirmed for example by Liu et al. (2020c), Marchetti et al. (2019, 2020). In particular, ionospheric anomalies (from ionosonde and Swarm satellite data) reported by De Santis et al. (2020), were detected from five months before the mainshock; at around 2 months before and finally on 2-3 June 2019 (under very quiet geomagnetic conditions). The authors pointed out that: 1) anticipation time, distance and features of the ionospheric anomalies were in agreement with the values estimated by using the Korsunova and Khegai $(2006,2008)$ method as a function of the magnitude of incoming earthquake (for $M=6-7$, the distance would be less than $600 \mathrm{~km}$, and the advance time from 1 to 6 days); 2) the results seem support the hypothesis that the observed percursors can be due to the release of ionized particles from the lithosphere (see Freund, 2011; Pulinets and Ouzounov, 2011; Hayakawa et al., 2018).

\section{DEMETER SATELLITE OBSERVATIONS}

In the previous century, the analyses of earthquake precursors in space were carried out with data collected by non-devoted satellites. The increasing interest in studying these phenomena resulted in the proposal of several missions - deigned for investigating the phenomenology with multi-instrumental payloads - such as DEMETER (Parrot, 2002), QuakeSat (Flagg et al., 2004), ESPERIA (Sgrigna et al., 2005a; Sgrigna et al., 2007; Sgrigna et al., 2008), VULKAN (Kuznetsov et al., 2011), CSES (Shen et al., 2018) and FORMOSAT-7/COSMIC-2 (Liu et al., 2020a). Between them, the French satellite DEMETER has been the first satellite devoted to investigate seismo-electromagnetic and volcanic phenomena (Lagoutte et al., 2006). The mission-started on 2004 and ended on 2010-was based on a payload including: a detector (ICE) of electric field components from quasi DC up to $3.5 \mathrm{MHz}$; a three axis search-coil magnetometer IMSC (from a few $\mathrm{Hz}$ up to $18 \mathrm{kHz}$ ); a couple of instruments for plasma investigations (ISL and IAP); and a high energy particle detector (IDP). The orbit was quasi Sunsynchronous circular with an inclination of about $98^{\circ}$, ascending node at 22:15 LT, altitude between about $710 \mathrm{~km}$ (up to 2005) and about $660 \mathrm{~km}$ (after 2005). All the instruments operated in two data acquisition modes (named survey and burst, at low and high data sampling rate respectively) between \pm 65 degrees of invariant latitude. It is neither possible to discuss in detail nor to summarize all published results based on DEMETER data. Therefore, in this review, we will mainly concentrate on the statistical studies and on the most assessed analysis methods, even though this will exclude to discuss some other interesting analyses. For the purpose of this review, we privilege presenting results obtained on many events with a procedure adopted by several authors.

\section{Electromagnetic Field Anomalies}

By analyzing quasi-static electric field data detected night-time by DEMETER for high magnitude earthquakes of Indonesia and Chile regions (Zhang et al., 2014), reported perturbations from 1.5 to $16 \mathrm{mV} / \mathrm{m}$, over the epicentre or at the end of seismic faults within $2000 \mathrm{~km}$ from the epicentre, before (in a time window of $-7 /+1$ day around the events) of 27 earthquakes. This value of about $10 \mathrm{mV} / \mathrm{m}$ measured in space should be reconciled with that measured on ground that is several order of magnitude higher, but never exceeding $100 \mathrm{~V} / \mathrm{m}$ over an area of $100-1,000 \mathrm{~km}$ around the epicentre and for middle-time observations (days) (Kondo, 1968; Vershinin et al., 1999; Hao et al., 2000; Rulenko, 2000). On 2010, DEMETER has detected an enhancement of ULF emissions two months around the Haiti earthquake (M7.0, January 12th, 21:53 UTC) (Athanasiou et al., 2011) and in occasion of the Chile event (M8.8, February 27th, 2010, 6:34 UTC), when also ELF and ionospheric perturbations were detected simultaneously (Zhang et al., 2011).

Probably the most significant result obtained with the DEMETER data is the statistical analysis - through the superposed epoch and space method - of the disturbances of the electric field power spectrum density (PSD) measured by the ICE experiment as function of the seismic activity (Nermek et al., 2008, 2009, 2010; Píša et al., 2013) According to this method, all earthquake occurrences and locations are placed at the origin of the resulting time-space diagram (time $=0$ and distance $=0$ ). The relative intensity of the electric PSD (evaluated by subtracting the background and normalizing by the SD) is plotted as a function of spatial and temporal distance between the satellite and the position and time for each analyzed earthquake. The first results of such a study of ICE data, published on 2008, included 2.5 years of observations, whereas the last analysis of 2013 was executed on 6.5 years, i.e., all the DEMETER database. Starting from the larger band of $1-2 \mathrm{kHz}$, analyzed on 2008 , the study has been refined on 2009 by restricting to PSD at $1.7 \pm$ $200 \mathrm{~Hz}$ (i.e., cantered on the waveguide cut-off frequency, see below for details). On 2013 the investigation have been extended 
to the whole range below $10 \mathrm{kHz}$ (with 16 bands of about $117 \mathrm{~Hz}$ each) in order to reduce the interference from VLF transmitters. In the most updated version of the study, only isolated earthquakes have been selected by excluding aftershocks as well as by filtering events belonging to seismic sequences preceding the main shock. Earthquakes have been classified in several categories as a function of magnitude and hypocentral depth. The temporal series of ICE data detected around each seismic event has been grouped in bins of $4 \mathrm{~h}$, since five days before up to three days after the earthquake. Geomagnetic conditions have been taken in account by categorizing data in four classes, based on Kp values, and by excluding data collected in geomagnetically perturbed periods. The impact of magnetic local time has also been investigated. By distinguishing dayside and nightside, a positive correlation has been found only for night-time data. Finally, observations have been tested against random dataset of earthquakes (casually shifted in time and longitude). The authors claim a very small but statistically significant decrease of the electric PSD at about $1.7 \mathrm{kHz}$, which starts a few hours before the earthquakes. The "peak" in the 2009 analysis includes 2068 "points" (observations) from 64 earthquakes and 2952 "points" from 369 earthquakes for the 2013 analysis. The involved distance of the claimed decrease is of less than $350 \mathrm{~km}$ on 2008 analysis (with a bin of $140 \mathrm{~km}$ ) and less than $440 \mathrm{~km}$ in the 2013 study. It worth to highlight that these results would be "compatible" with a raw estimation of the area involved in the mechanical precursors that could be done on the basis of the Dobrovolsky radius $\mathrm{r} \leq 10^{4.3 \mathrm{M}} \mathrm{km}$ (Dobrovolsky et al., 1979) that is of about 140 and $380 \mathrm{~km}$ for earthquake magnitude $\mathrm{M}=5$ and 6 respectively. The frequency of $1.7 \mathrm{kHz}$, where the decrease of wave intensity was observed, corresponds to the low-frequency cutoff for propagation in the Earth-ionosphere waveguide at night (Budden, 1961; Harrison et al., 2010). This frequency is inversely proportional to the height of lower boundary of the ionosphere. Electromagnetic waves generated by lightning in thunderstorms are a crucial source of VLF radiation (including whistlers) during the nighttime. Local variations of the electromagnetic conditions over the area of earthquake preparation could vary the cutoff frequency of the Earthionosphere waveguide affecting the electromagnetic spectrum observed by DEMETER at frequencies of about $1.7 \mathrm{kHz}$. A hypothesis could be that additional ionization of air molecules at the Earth's surface prior to earthquakes could increase the electrical conductivity of the lower troposphere. The height of the lower boundary of the ionosphere exhibits a seasonal variation, and it depends on the position of observation (Toledo-Redondo et al., 2012). It is therefore hard to compare observations of absolute values of VLF wave intensity, which depend on the positions and on season. In this framework, seasonal effects have been studied by dividing the ICE dataset in groups of three months. Even though non conclusive, the PSD analyses seem pointing out some dependence from the seasonal variation of lightning activity - that is globally larger between March and August - that could maximize the possibility to detect seismoelectromagnetic fluctuations. The decrease of wave intensity found in the cited ICE-DEMETER studies is of about $4-6 \mathrm{~dB}$ for the analysis of 2008, about 2.4-3.6 dB for the study published on 2009 and about $2 \mathrm{~dB}$ for the results of 2013. It is a small, but significant decrease of wave intensity as compared to the normal variability of about $11 \mathrm{~dB}$ (2009), and $\pm 7.5 \mathrm{~dB}$ (2013). The decrease does not occur directly above the earthquake epicentre, but is shifted about $2^{\circ}$ in the westward direction. Several hypothesis have been suggested for explaining this latitudinal shift such as aerosol drift, Coriolis contribution, ion drift, etc. (2009). The effect appears higher for higher geomagnetic latitudes (greater than $20^{\circ}$ ) (for analysis of 2010 and 2013). The decrease occurs more often close to shallower earthquakes: events with depth less than $40 \mathrm{~km}$. The effect is larger for larger magnitude: $\mathrm{M}>5.0$ (2009); $\mathrm{M}>5.5$ and threshold effect at $M=4$ (2013). With respect to the investigation of the effect of earthquakes occurring under sea/ land, no dependence has been found in the analyses of 2008-2009, whereas a greater effect has been pointed out for undersea earthquakes in the 2013 investigation. The statistical significance of the claimed observations has reduced from the initial value (more than 3б) (for 2008, 2009) obtained with 2.5 years up to the last published analysis carried out on the whole DEMETER database (2013). The ICE study disagrees with previous ones that mostly reported an increase in the ELF/VLF activity (Parrot et al., 1985; Larkina et al., 1989; Parrot and Mogilevsky, 1989; Serebryakova et al., 1992; Molchanov et al., 1993). However, we should cite that early studies have not used "control set of data" in order to estimate statistical significance of the observed effects. It is worth highlighting that, with a conservative and very laudable approach, the authors of the 2009 analysis wrote: " [...] although the correlation between seismic activity and intensity of electromagnetic waves is statistically significant, it is observed only due to the large number of the analyzed events. Therefore even if there is on average a decrease of wave intensity related to large surface earthquakes, individual events may exhibit rather different behavior; the natural fluctuations of intensity of electromagnetic waves are large and the observed effect is relatively weak as compared to them». Finally, it is worth highlighting that, even though the DEMETER studies have pointed out the evidence of electric field fluctuations, no effect has been found for magnetic field measurements carried out simultaneously by the same satellite.

The authors of (Parrot and Pinçon 2020) studied the existence of a spatial and temporal correlation between seismic activity and the whistler waves detected by the RNF neural network of DEMETER. On ground, Hayakawa, et al. (1993) have found a correlation between earthquakes and the occurrence of the anomalous whistlers, i.e., whistlers with anomalous dispersion. Whistlers are ELF-VLF right hand polarized emissions generated by lightning that can propagate in the Earth-ionosphere waveguide as well as through the ionosphere and the magnetosphere mainly ducted along the geomagnetic field lines. The authors reported a statistical increase of about $10 \%$ of the whistler rate the day before the earthquake (with $\mathrm{M} \geq 5.5$ and depth $\leq 20 \mathrm{~km}$, at a distance less than $200 \mathrm{~km}$ ) with respect to the background (evaluated between -15 and 5 days around the earthquake time). On the other side, no significant correlation was observed for earthquakes of magnitude lower or equal to 5.2, 
which could point out both the difficulty and the sensitivity of the applied overlapping epoch's method to identify such an increase. It is worth highlighting the prudence of the authors when they remarks that even though their observation confirms the detectability from space of a LAIC mechanism prior to large and shallow earthquakes, their studies cannot support any forecast or deterministic association of anomalies detection with the occurrence of a single seismic events. The existence of LAIC coupling mechanism is an excellent reason to study short-term precursors.

\section{Ion and Electron Density Fluctuations}

Several analyses of DEMETER satellite data have shown an increase of the number and intensity of the ionospheric perturbations detected before the occurrence of strong earthquakes as well as an increase of the perturbations amplitude as a function of the magnitude (Parrot, 2011). In particular, Píša et al. (2011) has pointed out a significant increase of the plasma density detected by DEMETER tens of days before the main shock of the Chile earthquake on February 27, 2010.

Li and Parrot (2012) have analyzed ion density (defined as the sum of $\mathrm{H}+, \mathrm{He}+, \mathrm{O}+$ from IAP)) and the electron density (from ISL) data collected in the whole DEMETER activity along 6.5 years and registered only for night-time. The authors have selected 21.863 earthquakes from the USGS catalog, with magnitude grater or equal than 4.8 and distance between DEMETER and the epicentre $\leq 1,500 \mathrm{~km}$, with a time window of 15 days before earthquake and measurements collected in quiet days $(\mathrm{Kp}<3)$. In addition, observations have been tested against random dataset of earthquakes (casually shifted in time of one month, in the same season, and in longitude of $25^{\circ}$ ). The ion density perturbations mainly consist of an increase. The fraction of precursor observations increases of few percent with the earthquake magnitude. The mean number of perturbations per earthquake is larger for stronger events. Both the good detections and the number of false alarms decrease as a function of the perturbations amplitude (whatever is the magnitude of the earthquakes). This means that the amplitude of the perturbations is not well related to the magnitude. By studying the mean and median values of perturbations amplitude plotted vs. magnitude, the authors claim that: stronger earthquake apparently show larger perturbations; this effect is only evident for very large magnitude and other earthquake parameters (different from magnitude) could play a role. Results for electron density are similar to those for ion density. In order to analyze of the effect of the earthquakes location, the epicentres have been classified such as inland, below sea (water depth $>1 \mathrm{~km}$ ), and close coast (depth $<1 \mathrm{~km}$ ). The author's conclusions are that the percentage of good detections increases with the magnitude whatever is the earthquake location. The percentage of good detections is larger for earthquake occurring below the sea. Earthquake taking place near coasts have the lowest percentage of good detections. The mean number of perturbations smoothly increase the days before the seismic event. Anyway, the authors emphasize that - beyond the spatial and temporal correlation between observations and seismic events - there is no further way to assert a causal relationship between earthquakes and observed anomalies. Ryu et al. (2014) and Ryu et al. (2016) have studied the statistical impact of earthquakes, of $M>5.0$ and $M \geq 6.0$ respectively, (mainly occurring in the equatorial region) on the electron density data measured by the DEMETER satellite in the period 2005-2010. By correlating the indices of daily seismic activity and the EIA (equatorial ionization anomaly) intensity, the authors obtained statistically significant values of the lagged cross-correlation function. The results show the existence of ionospheric precursors of low-latitude earthquakes and that their concur in enhancing the equatorial anomaly.

More recently, machine-learning methods have been applied for the automatic identification of earthquake precursors (Xiong et al., 2020; Xiong et al., 2021). The new research field is extremely interesting and further results can be achieved. DEMETER data have been analyzed in hundreds of publications. For a summary, we address the reader to the general review Parrot (2018) and to the specific articles (such as for example Parrot, 2012; Zlotnicki et al., 2010; Zlotnicki et al., 2013; Parrot, and Li, 2015; Liu et al., 2015; Ho et al., 2018; Parrot and Li, 2018; Parrot et al., 2021).

\section{FIRST ANALYSES FROM THE CSES SATELLITE MISSION}

As described in previous sections, after the earliest studies with not devoted satellites, the DEMETER observations have supported an increasing number of studies claiming the existence of seismo-associates ionospheric and magnetospheric perturbations occurring from two weeks up to few hours before earthquakes. In this framework, the CSES satellite is the second mission designed for investigating seismo-associated phenomena from space, which has successfully been launched on February 2018. CSES payload includes nine instruments: a particle detector from China constituted by three sub-units [the HEPP-L, - $\mathrm{H}$ and -X detectors (Li M. et al., 2019) for measuring low- and highenergy charged particles and $\mathrm{X}$ rays]; the Italian HEPD highenergy particle detector (Alfonsi et al., 2017; Ambrosi et al., 2018, 2020; Picozza et al., 2019; Bartocci et al., 2020; Sotgiu et al., 2021); two magnetometers [HPM (Cheng et al., 2018) for low and SCM (Cao et al., 2018) for high frequencies respectively]; the EFD detector (Huang et al., 2018) (for measuring electric field components); a Langmuir probe (LAP) (Yan et al., 2018a; Liu et al., 2019) and a plasma detector PAP (Liu et al., 2019b); a three bands beacon transmitter and a occultation receiver (Chen et al., 2018; Lin et al., 2018). After two years of data acquisitions, the temporal series starts to be enough long to allow carrying out statistical studies. In the following, we discuss some of the last published results.

Yan et al. (2018b) reported the observations by CSES of unusual ionospheric irregularities of (electromagnetic field, plasma, and energetic particle fluxes) over the epicentral area and before four earthquakes of magnitude greater than 7 . Perturbations have been recorded by several CSES instruments (such as EFD, SCM, LAP, PAP and HEPP) during night-time orbits. The authors claim a correlation with the earthquake 
hypocentral depth (the deeper the earthquake hypocentre was the fewer were the anomalous irregularities observed) and with the magnitude (the greater was the magnitude, the greater were the observed electromagnetic disturbances). In the analysis, measurements gathered in geomagnetically disturbed period (i.e., $\mathrm{Kp}$ index greater than 3 or the Dst index lower than $-20 \mathrm{nT}$ ) have been excluded. The studied earthquakes occurred all at low latitude on August 2018 in: New Caledonia $(M=7.1)$, Venezuela $(M=7.3)$, Fiji islands $(M=8.1)$ and Peru $(M$ = 7.1). Unfortunately, for the studied earthquakes none observations have been carried out spatially and temporally near to the epicentres. Therefore, the claimed perturbations have been evaluated as anomalous with respect a background level computed with a spatial resolution of some degrees (i.e., on the basis of measurements done quite far from the epicentre) and with a poor temporal resolution (i.e., there is not a temporal series of repeated measurements before/after the events in the same place). Recently, Zhu et al. (2021) published the most up-to-date CSES data analysis (over more than 2.5 years of electron density and temperature measurements) that would support a temporal and spatial correlation between the occurrence of earthquakes with $\mathrm{Ms} \geq 4.8$ and the observation of positive variations of $\mathrm{Ne}$ and negative variations of $\mathrm{Te}$ (during nighttime hours), approximately one and two weeks before the seismic events, at a distance of less than about $200 \mathrm{~km}$ from the epicenters (apparently within the Dobrovolsky's radius). However, the authors declare, similarly to other reports on earthquake precursors, the anomalous variation of parameters has not been revealed in all studied earthquakes and the perturbations seems can occur at various temporal and spatial distances from the epicentre. On the other side, the ionospheric and geomagnetic dynamics driven by the solar activity cannot rule out other possibilities as sources of the observed anomalies.

Several authors (Pulinets, 2012; Parrot, 2013; Kuo et al., 2014; Oikonomou et al., 2016) have suggested that the increase of ionization over the zone of impending earthquake (registered by ground-based TEC measurements and electron density satellite observations) could have a significant impact on the equatorial ionospheric anomaly (EIA). Marchetti et al. (2020) have studied the anomalies (defined with respect to the EIA background variability) of the electron density measured by CSES and Swarm in eight months preceding the $\mathrm{M}=7.5$ Indonesia earthquake occurred on September 28th, 2018. An increase of atmospheric (mainly in aerosol optical thickness, skin temperature and water vapor) and ionospheric anomalies were reported about 3.7 and 2.7 months respectively before the mainshock, while on August 2, 2018 an anomaly was detected simultaneously in atmosphere (aerosol content), topside ionosphere (electron density detected by CSES) and in the Swarm magnetic field. Finally, on August 19th, 2018 an enhancement of the electron density was detected by Swarm and CSES over the area of the preparing earthquake and in the conjugated zone (during nighttime). These observations confirm the DEMETER analyses of Ryu et al. (2014), Ryu et al. (2016) about the impact of the earthquake preparation phase on the EIA.

In the article Xuhui, et al. (2020) recently published, CSES measurements possibly reconciled with 12 earthquakes with magnitude $M \geq 7$ have been analyzed. The authors report the observation of various anomalies of several parameters measured by the on board instruments, on different spatial and temporal scales (from days to weeks before the events). In particular, in occasion of the Ms = 7.1 earthquake - occurred in Mexico on February 17, 2018 - the authors report: 1) disturbances of low-frequency PSD of the electric field (at 155.5 and $1.405 \mathrm{kHz}$ ) one and two days before the seismic event; 2) fluctuations of ionospheric parameters (such as electrons density and temperature, and $\mathrm{NO}+$ density) two days before the event. The article is a short report aimed at summarizing the results of the CSES program (that will be published in further specific reports) that does not allow a complete comprehension of the achieved results.

Li et al. (2020) have analyzed electron and ion oxygen density measured by ISL and IAP (Li and Parrot, 2012) on board the DEMETER mission (in about 6.5 years) and by LAP and PAP on board of the CSES satellite (in more than one year). The authors have searched for correlations with seismic events occurred within a distance less than $1,500 \mathrm{~km}$ from the satellite ground trace and in a time window of 15 days before the earthquakes. The authors claim that the detection rate of seismo-ionospheric perturbations increases as a function of: 1) the time resolution of satellite data acquisition and 2) the earthquake magnitude; whereas decreases as the epicentral depth of seismic events increases. They also claim that the occurrence rate of these ionospheric variations is the highest the day of the earthquake and then gradually decreases the day before. More precisely, in some areas, the observed ionospheric perturbations mainly occur about 6-7 days prior to earthquakes confirming the observations of (Akselevich and Tertyshnikov, 1995) and (Liu et al., 2009) and the analysis of Li M. et al. (2019) who found that ionospheric variations gain a high climax 3 days before the Wenchuan main event on May 12, 2008.

Even though up to now, the reported CSES analyses are not conclusive, the large amount of observations from instruments will significantly help in studying frequencies, amplitudes and characteristics of ionospheric perturbations related to earthquakes and possibly their generation mechanisms.

\section{CONNECTING PERTURBATIONS ON GROUND AND IN SPACE}

As previously mentioned the value of preseismic quasi-static electric field amplitude measured in space is of about $10 \mathrm{mV} /$ $\mathrm{m}$ (Zhang et al., 2014) while that measured on ground is several order of magnitude higher, but never exceeding $100 \mathrm{~V} / \mathrm{m}$ over an area of $100-1,000 \mathrm{~km}$ around the epicentre and for middle-time observations (days) Kondo (1968); Vershinin et al. (1999); Hao et al. (2000); Rulenko (2000). In order to reconcile such groundbased and space-based observations, Sorokin et al. (2001) suggested that radon gas exhalations in the atmosphere would generate a flow of large negative aerosol particles moving upward with a velocity of a few $\mathrm{cm} / \mathrm{s}$ together with smaller positive aerosol particles moving at lower velocity. The difference of speeds between the two fluxes would cause a local electric field 
impulse of tens $\mathrm{kV} / \mathrm{m}$ on a temporal scale of less than tens of minutes (Liperovsky et al., 2008b) but, because this electric field is confined between such layers of aerosols clouds, it will not affect regions external to the layers. Therefore, this mechanism would not be able to explain the quasi-static electric field observed in the ionosphere before earthquakes on the scale of hundreds or thousands of kilometres. In general, the hypothesis that ionospheric quasi-static electric field could be induced by radon emissions is highly debated. The releases of gas, aerosol and other radioactive sources can vary the local ionization through alpha and gamma decays - which could change up to two times the conductivity of the lower layers of the atmosphere (Omori et al., 2009). Anyway, by assuming a radon exhalation of $10 \mathrm{~Bq} / \mathrm{m}^{3}$, Omori et al. (2009) estimated an increase of the conductivity of only 1.5 times, not enough to generate a significant variation the background electric field up to about $10 \mathrm{mV} / \mathrm{m}$ observed in the ionosphere. Similarly, even doubling the ionization rate by radon will result into a variation $10 \%$ of the electric field between Earth and ionosphere (Harrison, et al., 2010).

More in general, a direct propagation of an electric field from the lithosphere up to the ionosphere seems in contradiction with observations. The value of the electric field in the ionosphere have been estimated by several authors (Kim and Hegai, 1999; Denisenko et al., 2008) by assuming a given value on ground as well as different geometries, distributions and conditions. In night-time, the intensity of quasi-static electric field on ground needed to obtain the observed intensity of $10 \mathrm{mV} / \mathrm{m}$ in space would be at least one order of magnitude higher than the maximum one observed at the surface in the preparation zone. In daytime, when the conductivity in the ionosphere is one or two orders of magnitude larger than in night-time, the electric field value in space would be of the order of $10^{-3} \mathrm{mV} / \mathrm{m}$, well lower than the observed value of $10 \mathrm{mV} / \mathrm{m}$. This conclusion seems confirmed by the estimation of the damping of the electric field from ground to the ionosphere observed about intense thunderstorm events (Park and Dejnakarintra 1973). In fact, measurements of quasi-static electric field during tropical cyclones can be of about $(1-10) \mathrm{kV} / \mathrm{m}$ on ground (Park and Dejnakarintra 1973) and in space up to about $25 \mathrm{mV} / \mathrm{m}$, as recorder at an altitude of about $950 \mathrm{~km}$ over intense thunderstorms by the COSMOS-1809 satellite (together with plasma density fluctuation of about 6\%) (Isaev et al., 2002; Sorokin et al., 2005). Therefore, the amplitude of the quasistatic electric field on ground during intense thunderstorms is of some order of magnitude higher than the highest ever measured/claimed on ground about earthquakes.

\section{CONCLUSION}

It is extremely hard to take conclusions in a so large field with this variety of observations, methods, hypothesis, models and sometime speculations. Therefore, we will limit to draw some considerations.

- Variability of electromagnetic precursors
The interpretation of claimed electromagnetic precursors is promising, but still in some early stage: there is a large variability of the detected intensity, frequencies, spatial and temporal distribution, spreading or clustering around the epicentre or along geomagnetically connected areas, etc. After the early sparse observations, even with the most recent devoted missions such as DEMETER, CSES, and FORMOSAT the phenomenology is still barely understood.

- What transfers the information from ground to space?

Based on the observations of an enhancement of VLF fluctuations in the range of acoustic gravity waves measured before some earthquakes, the link between AW/AGW and VLF disturbances seems quite well assessed. On the other side the conclusion that the observed phenomenology has a preseismic character asks for further confirmations, because the connection is still indirect. Several reports are in favor of a LAIC due to the chain of ionization, changes of conductivity and feedback phenomena originated by radon emissions.

- Correlation between earthquake magnitude, depth and amplitude of possible precursors

The published analyses about groundwater level variations and radon gas exhalations seems suggest a correlation between the earthquakes magnitude and the amplitude and spatial/ temporal distributions of their claimed precursors. Reports about electromagnetic precursors seem not univocal, but the variation of the electric field intensity at the ionospheric cutoff is more intense when the magnitude is higher (Němec et al., 2009; Píša et al. (2013). Nevertheless the vast majority (if not all) of the analyses cited in this review that found precursors were conducted on earthquakes of magnitude greater than 5 , and a significant percentage of the case studies cited were for even higher magnitudes (6 or greater). This consideration - which remains generally valid for the vast literature on the subject - shows that magnitude should be a key parameter in precursor identification. A similar role is played by hypocentral depth: most reports of seismic precursors concern shallow earthquakes, although we do not have a clear or unique threshold for depth, partly because differences in the specific seismic-tectonic conditions of different areas should not be overlooked. Thus, we could summarize that the larger the magnitude and the smaller the depth of the earthquake, the greater the chances of detecting the earthquake effects at satellite altitudes. Otherwise, it would be rather difficult (if not impossible) to detect these ionospheric or magnetospheric effects. Obviously, it cannot be ignored that, the dependence from the earthquake magnitude can cause a threshold of detectability and that unfortunately, the cut on magnitude reduces significantly the statistics, which can affect the significance of the conclusions. However, a clear proportionality between the earthquake intensity and the numerousness, frequency and/or amplitude of the presumed pre-seismic anomalies is necessary to link together the two kind of phenomena. Higher-sensitivity instruments foreseen for next satellites will allow a better definition of this correlation.

- Extent of the spatial scale of the precursors 
The densification of precursor observations within few hundreds of kilometres from the epicentre - i.e., near the larger earthquake deformations - seems coherent with the postulated dependence of the precursor generation mechanism from the size of the involved faults and the magnitude of the resulting earthquake. The distance of ionospheric precursors could be correlated with magnitude [see for example the model of Korsunova and Khegai (2006), Korsunova and Khegai (2008)]. However, is still missing an estimation of the area that could be involved in the generation mechanism of various (not only mechanical) earthquake-precursors as well as of the extension of detectability region in which the signal to noise ratio would allow a reliable precursors recognition.

- Temporal advance and clustering of anomalous observations

The largest electromagnetic anomalies (measured hours or days before large events) seem occur more frequently in time and with larger amplitude close to the incoming earthquake. Moreover, it is worth highlighting the recent hypothesis (and first confirmations) that also ionospheric precursors would follow Rikitake's law that larger earthquakes should be associated with a longer precursor times. This could be reconciled with the critical nature of the process originating the earthquake in the preparation phase along the fault before the rupture.

The variety of phenomena associated with earthquakes requires the simultaneous observation of many parameters. The need for statistical studies that increase the reliability of results by reducing background effects asks for increasing the number of seismic events analyzed worldwide. Both of these requirements, for a global coverage system, can only be met from space through satellite remote sensing. In this framework will be particularly valuable the new multi-spacecraft missions.

On 2019 have been launched the six small satellites of the FORMOSAT-7/COSMIC-2 constellation (Lin et al., 2020). The satellites - initially deployed into a circular orbit at $720 \mathrm{~km}$ - will take about 16 months to reach the mission orbit at $550 \mathrm{~km}$ with 24 degrees of inclination. The satellites are equipped with a radio occultation system (TGRS) designed for 3D sounding of electron density; the IVM instrument (for in-situ observations of ion density, temperature, and drift); and a RF beacon. From IVM

\section{REFERENCES}

Akselevich, V. I., and Tertyshnikov, A. V. (1995). Methodology of Ecological Monitoring Data Application to Seismic Forecasting. Atmospheric Oceanic. Optics C/C Optika Atmosphri Okena 8, 567-569.

Aleksandrin, S. Y., Galper, A. M., Grishantzeva, L. A., Koldashov, S. V., Maslennikov, L. V., Murashov, A. M., et al. (2003). High-energy Charged Particle Bursts in the Near-Earth Space as Earthquake Precursors. Ann. Geophys. 21 (2), 597-602. doi:10.5194/angeo-21-597-2003

Aleshina, M. E., Voronov, S. A., Gal'Per, A. M., Koldashov, S. V., and Maslennikov, L. V. (1992). Correlation between Earthquake Epicenters and Regions of HighEnergy Particle Precipitations from the Radiation belt. Cosmic Res. 30 (1), 65-68. measurements of the ion velocity, it is also possible to estimate the electric field. The FORMOSAT-7/COSMIC-2 mission offers the unique capabilities: 1) to carry simultaneously both vertical soundings of the ionospheric and in-situ plasma observations; and 2) to provide measurements with a constellation of six satellites (Ho et al., 2020). These features will allow investigating pre-, co- and post-seismic phenomena with a high-resolution (in time and space) measurements at low latitude (Liu et al., 2020b). Some preliminary results - about the Bitung Indonesia earthquake of November 14, 2019, M7.1 (with an increase of TEC, NmF2 and HmF2 over the epicentre on 25-26 October 2019) - appear already interesting (Liu et al., 2020b).

On 2023 will be launched CSES-02, the second mission of the CSES series, with the same multi-instrumental payload and similar orbital parameters of the first satellite, that will allow reducing the revisit time between the consecutive observations of the same geographic region.

Earthquake precursors are extremely elusive and difficult to be observed, immersed as they are in a variety of other natural and anthropogenic signals - with amplitudes even orders of magnitude greater - that can cover them and easily induce erroneous interpretations. However, the set of observed precursors is remarkable and so varied to provide confidence to the efforts of the vast scientific community that deals with them. Observations from space, especially with multi-satellite missions and constellations, will be able to contribute significantly to clarifying this picture.

\section{AUTHOR CONTRIBUTIONS}

All authors listed have made a substantial, direct, and intellectual contribution to the work and approved it for publication.

\section{FUNDING}

This work was supported by the Italian Space Agency in the framework of the "Accordo Attuativo 2020-32.HH.0 Limadou Scienza+" (CUP F19C20000110005)

Alfonsi, L., Ambroglini, F., Ambrosi, G., Ammendola, R., Assante, D., Badoni, D. et al. (2017). The HEPD Particle Detector and the EFD Electric Field Detector for the CSES Satellite. Radiat. Phys. Chem. 137, 187-192. doi:10.1016/ j.radphyschem.2016.12.022

Ambrosi, G., Bartocci, S., Basara, L., Battiston, R., Burger, W. J., Campana, D., et al. (2020). Beam Test Calibrations of the HEPD Detector on Board the China Seismo-Electromagnetic Satellite. Nucl. Instr. Methods Phys. Res. Section A: Acc. Spectrometers, Detectors Associated Equipment 974, 164170. doi:10.1016/ j.nima.2020.164170

Ambrosi, G., Bartocci, S., Basara, L., Battiston, R., Burger, W. J., Carfora, L., et al. (2018). The HEPD Particle Detector of the CSES Satellite mission for Investigating Seismo-Associated Perturbations of the Van Allen Belts. Sci. China Technol. Sci. 61 (5), 643-652. doi:10.1007/ s11431-018-9234-9 
Antselevich, M. G. (1966). The Influence of Tashkent Earthquake on the Earth's Magnetic Field and the Ionosphere. Tashkent Earthquake 26, 187-188.

Athanasiou, M. A., Anagnostopoulos, G. C., Iliopoulos, A. C., Pavlos, G. P., and David, C. N. (2011). Enhanced ULF Radiation Observed by DEMETER Two Months Around the strong 2010 Haiti Earthquake. Nat. Hazards Earth Syst. Sci. 11 (4), 1091-1098. doi:10.5194/nhess-11-1091-2011

Bartocci, S., Battiston, R., Burger, W. J., Campana, D., Carfora, L., Castellini, G., et al. (2020). Galactic Cosmic-Ray Hydrogen Spectra in the 40-250 MeV Range Measured by the High-Energy Particle Detector (HEPD) on Board the CSES-01 Satellite between 2018 and 2020. ApJ 901 (1), 8. doi:10.3847/1538-4357/abad3e

Battiston, R., and Vitale, V. (2013). First Evidence for Correlations between Electron Fluxes Measured by NOAA-POES Satellites and Large Seismic Events. Nucl. Phys. B - Proc. Supplements 243-244, 249-257. doi:10.1016/ j.nuclphysbps.2013.09.002

Biagi, P. F., Ermini, A., Kingsley, S. P., Khatkevich, Y. M., and Gordeev, E. I. (2001). Difficulties with Interpreting Changes in Groundwater Gas Content as Earthquake Precursors in Kamchatka, Russia. J. Seismology 5 (4), 487-497. doi:10.1023/A:1012015317086

Blackett, M., Wooster, M. J., and Malamud, B. D. (2011). Exploring Land Surface Temperature Earthquake Precursors: A Focus on the Gujarat (India) Earthquake of 2001. Geophys. Res. Lett. 38 (15), 15303. doi:10.1029/ 2011GL048282

Bortnik, J., Bleier, T. E., Dunson, C., and Freund, F. (2010). Estimating the Seismotelluric Current Required for Observable Electromagnetic Ground Signals. Ann. Geophys. 28 (8), 1615-1624. doi:10.5194/angeo-28-1615-2010

Bortnik, J., and Bleier, T. (2004). Full Wave Calculation of the Source Characteristics of Seismogenic Electromagnetic Signals as Observed at LEO Satellite Altitudes. San Francisco: AGU Fall Meeting Abstracts.

Bryant, N. A., and Nathan, R. B. (2003). Observed Weather Satellite Thermal Responses Prior to and after Earthquakes, T52D-04. San Francisco: AGU Fall Meeting Abstracts.

Budden, K. G. (1961). The Wave-Guide Mode Theory of Wave Propagation. London: Logos Press.

Cao, J., Zeng, L., Zhan, F., Wang, Z., Wang, Y., Chen, Y., et al. (2018). The Electromagnetic Wave experiment for CSES mission: Search Coil Magnetometer. Sci. China Technol. Sci. 61 (5), 653-658. doi:10.1007/s11431018-9241-7

Cenni, N., Viti, M., and Mantovani, E. (2015). Space Geodetic Data (GPS) and Earthquake Forecasting: Examples from the Italian Geodetic Network. Bollettino di Geofisica Teorica ed Applicata 56 (2), 129-150. doi:10.4430/ bgta0139

Chakraborty, S., Sasmal, S., Chakrabarti, S. K., and Bhattacharya, A. (2018). Observational Signatures of Unusual Outgoing Longwave Radiation (OLR) and Atmospheric Gravity Waves (AGW) as Precursory Effects of May 2015 Nepal Earthquakes. J. Geodynamics 113, 43-51. doi:10.1016/ j.jog.2017.11.009

Chen, L., Ou, M., Ou, M., Yuan, Y., Sun, F., Yu, X., et al. (2018). Preliminary Observation Results of the Coherent Beacon System Onboard the China Seismo-Electromagnetic Satellite-1. Earth Planet. Phys. 2 (6), 1-10. doi:10.26464/epp2018049

Cheng, B., Zhou, B., Magnes, W., Lammegger, R., and Pollinger, A. (2018). High Precision Magnetometer for Geomagnetic Exploration Onboard of the China Seismo-Electromagnetic Satellite. Sci. China Technol. Sci. 61 (5), 659-668. doi:10.1007/s11431-018-9247-6

Chesnokov, V. Y., Galper, A. M., Kirillov-Ugryumov, V. G., Koldashov, S. V., Mikhailov, V. V., Popov, A. V., et al. (1987). Registration of Sporadic Increase of High Energy Particle Flux Near the Brazilian Anomaly Region. Int. Cosmic Ray Conf. 4, 451.

Chmyrev, V. M., Isaev, N. V., Bilichenko, S. V., and Stanev, G. (1989). Observation by Space-Borne Detectors of Electric fields and Hydromagnetic Waves in the Ionosphere over an Earthquake centre. Phys. Earth Planet. Interiors 57 (1-2), 110-114. doi:10.1016/0031-9201(89)90220-3

Cicerone, R. D., Ebel, J. E., and Britton, J. (2009). A Systematic Compilation of Earthquake Precursors. Tectonophysics. 476, 371-396. doi:10.1016/ j.tecto.2009.06.008

Conti, L., Picozza, P., and Sotgiu, A. (2021). A Critical Review of Ground Based Observations of Earthquake Precursors. Front. Earth Sci. Sec. Geohazards Georisks. doi:10.3389/feart.2021.676766
Cuomo, V., Filizzola, C., Pergola, N., Pietrapertosa, C., and Tramutoli, V. (2004). A Self-Sufficient Approach for GERB Cloudy Radiance Detection. Atmos. Res. 72 (1-4), 39-56. doi:10.1016/j.atmosres.2004.03.030

Datchenko, E. A., Ulomov, V. I., and Chernyshova, C. P. (1972). Electron Density Anomalies as the Possible Precursor of Tashkent Earthquake. Dokl. Uzbek. Acad. Sci. 12, 30-32.

Dautermann, T., Calais, E., Haase, J., and Garrison, J. (2007). Investigation of Ionospheric Electron Content Variations before Earthquakes in Southern California, 2003-2004. J. Geophys. Res. 112 (2). doi:10.1029/ 2006JB004447

De Santis, A., Abbattista, C., Alfonsi, L., Amoruso, L., Campuzano, S. A., Carbone, M., et al. (2019a). Geosystemics View of Earthquakes. Entropy 21 (4), 412. doi:10.3390/e21040412

De Santis, A., Balasis, G., Pavón-Carrasco, F. J., Cianchini, G., and Mandea, M. (2017). Potential Earthquake Precursory Pattern from Space: The 2015 Nepal Event as Seen by Magnetic Swarm Satellites. Earth Planet. Sci. Lett. 461, 119-126. doi:10.1016/j.epsl.2016.12.037

De Santis, A., Cianchini, G., Marchetti, D., Piscini, A., Sabbagh, D., Perrone, L., et al. (2020). A Multiparametric Approach to Study the Preparation Phase of the 2019 M7.1 Ridgecrest (California, United States) Earthquake. Front. Earth Sci. 8, 478. doi:10.3389/feart.2020.540398

De Santis, A., De Franceschi, G., Spogli, L., Perrone, L., Alfonsi, L., Qamili, E., et al. (2015). Geospace Perturbations Induced by the Earth: The State of the Art and Future Trends. Phys. Chem. Earth, Parts A/B/C 85-86, 17-33. doi:10.1016/ j.pce.2015.05.004

De Santis, A., Marchetti, D., Pavón-Carrasco, F. J., Cianchini, G., Perrone, L. Abbattista, C., et al. (2019b). Precursory Worldwide Signatures of Earthquake Occurrences on Swarm Satellite Data. Sci. Rep. 9 (1), 20287. doi:10.1038/ s41598-019-56599-1

De Santis, A., Marchetti, D., Spogli, L., Cianchini, G., Pavón-Carrasco, F. J., Franceschi, G. D., et al. (2019c). Magnetic Field and Electron Density Data Analysis from Swarm Satellites Searching for Ionospheric Effects by Great Earthquakes: 12 Case Studies from 2014 to 2016. Atmosphere 10 (7), 371. doi:10.3390/atmos10070371

Denisenko, V. V., Boudjada, M. Y., Horn, M., Pomozov, E. V., Biernat, H. K., Schwingenschuh, K., et al. (2008). Ionospheric Conductivity Effects on Electrostatic Field Penetration into the Ionosphere. Nat. Hazards Earth Syst. Sci. 8 (5), 1009-1017. doi:10.5194/nhess-8-1009-2008

Dey, S., and Singh, R. P. (2003). Surface Latent Heat Flux as an Earthquake Precursor. Nat. Hazards Earth Syst. Sci. 3 (6), 749-755. doi:10.5194/nhess-3749-2003

Dobrovolsky, I. P., Zubkov, S. I., and Miachkin, V. I. (1979). Estimation of the Size of Earthquake Preparation Zones. Pageoph. 117 (5), 1025-1044. doi:10.1007/ BF00876083

Dungey, J. W. (1963). Loss of Van Allen Electrons Due to Whistlers. Planet. Space Sci. 11 (6), 591-595. doi:10.1016/0032-0633(63)90166-1

Endo, T., Kasahara, Y., Hobara, Y., Sue, T., and Hayakawa, M. (2013). A Note on the Correlation of Seismo-Ionospheric Perturbations with Ground Motions as Deduced from F-Net Seismic Observations. Jae 33 (1), 69-76. doi:10.1541/ jae.33.69

Fidani, C., and Battiston, R. (2008). Analysis of NOAA Particle Data and Correlations to Seismic Activity. Nat. Hazards Earth Syst. Sci. 8 (6), 1277-1291. doi:10.5194/nhess-8-1277-2008

Fidani, C. (2018). Improving Earthquake Forecasting by Correlations between strong Earthquakes and NOAA Electron Bursts. Terr. Atmos. Ocean. Sci. 29 (2), 117-130. doi:10.3319/TAO.2017.10.06.01

Filizzola, C., Pergola, N., Pietrapertosa, C., and Tramutoli, V. (2004). Robust Satellite Techniques for Seismically Active Areas Monitoring: a Sensitivity Analysis on September 7, 1999 Athens's Earthquake. Phys. Chem. Earth, Parts A/B/C 29 (4-9), 517-527. doi:10.1016/j.pce.2003.11.019

Fishkova, L. M., Gokhberg, M. B., and Pilipenko, V. A. (1985). Relationship between Night Airglow and Seismic Activity. AnGeo 3, 689-694. Available at: https://ui.adsabs.harvard.edu/abs/1985AnGeo...3..689F/abstract.

Flagg, S., Bleier, T., Dunson, C., Doering, J., DeMartini, L., Clarke, P., et al. (2004). "Using Nanosats as a Proof of Concept for Space Science Missions: QuakeSat as an Operational Example," in Annual AIAA/USU Conference on Small Satellites (Logan: SSC04-IX-4), 1-12. Available at: https://digitalcommons.usu.edu/cgi/ viewcontent.cgi?article $=1728$ and context $=$ smallsat. 
Freund, F. (2011). Pre-earthquake Signals: Underlying Physical Processes. J. Asian Earth Sci. 41 (4-5), 383-400. doi:10.1016/j.jseaes.2010.03.009

Freund, F. T., Takeuchi, A., Lau, B. W. S., Al-Manaseer, A., Fu, C. C., Bryant, N. A., et al. (2007). Stimulated Infrared Emission from Rocks: Assessing a Stress Indicator. eEarth 2 (1), 7-16. www.electronic-earth.net/2/7/2007/. doi:10.5194/ ee-2-7-2007

Friis-Christensen, E., Lühr, H., Knudsen, D., and Haagmans, R. (2008). Swarm - an Earth Observation Mission Investigating Geospace. Adv. Space Res. 41 (1), 210-216. doi:10.1016/j.asr.2006.10.008

Fu, C.-C., Lee, L.-C., Ouzounov, D., and Jan, J.-C. (2020). Earth's Outgoing Longwave Radiation Variability Prior to $M \geq 6.0$ Earthquakes in the Taiwan Area during 2009-2019. Front. Earth Sci. 8, 364. doi:10.3389/feart.2020.00364

Fu, C.-C., Yang, T. F., Chen, C.-H., Lee, L.-C., Wu, Y.-M., Liu, T.-K., et al. (2017). Spatial and Temporal Anomalies of Soil Gas in Northern Taiwan and its Tectonic and Seismic Implications. J. Asian Earth Sci. 149, 64-77. doi:10.1016/ j.jseaes.2017.02.032

Galper, A. M., Dimitrenko, V. B., Nikitina, N. V., Grachev, V. M., and Ulin, S. E. (1989). Interrelation between High-Energy Charged Particle Fluxes in the Radiation belt and Seismicity of the Earth. Cosmic Res. 27, 789.

Galperin, Y. I., Gladyshev, V. A., Dzhordzhio, N. V., Larkina, V. I., and Mogilevskij, M. M. (1992). Energetic Particles Precipitation from the Magnetosphere above the Epicenter of Approaching Earthquake. Kosmicheskie Issledovaniya 30 (1), $89-106$.

Geller, R. J. (1997). Earthquake Prediction: a Critical Review. Geophys. J. Int. 131 (3), 425-450. doi:10.1111/j.1365-246X.1997.tb06588.x

Geller, R. J., Jackson, D. D., Kagan, Y. Y., and Mulargia, F. (1997). Earthquakes Cannot Be Predicted. Science 275 (5306), 1616. doi:10.1126/ science.275.5306.1616

Gokhberg, M. B., Pilipenko, V. A., and Pokhotelov, O. A. (1983). Satellite Observation of Electromagnetic Radiation over the Epicentral Region of an Incipient Earthquake. Dokl. Akad. Nauk. SSSR Earth Sci. Ser. Engl. Transl. 268 (1), 5-7.

Gousheva, M., Danov, D., Hristov, P., and Matova, M. (2009). Ionospheric QuasiStatic Electric Field Anomalies during Seismic Activity in August-September 1981. Nat. Hazards Earth Syst. Sci. 9 (1), 3-15. doi:10.5194/nhess-9-3-2009

Gousheva, M., Danov, D., Hristov, P., and Matova, M. (2008). Quasi-static Electric fields Phenomena in the Ionosphere Associated with Pre- and post Earthquake Effects. Nat. Hazards Earth Syst. Sci. 8 (1), 101-107. doi:10.5194/nhess-8-1012008

Gulia, L., and Wiemer, S. (2019). Real-time Discrimination of Earthquake Foreshocks and Aftershocks. Nature 574 (7777), 193-199. doi:10.1038/ s41586-019-1606-4

Hao, J., Tang, T., and Li, D. (2000). Progress in the Research on Atmospheric Electric Field Anomaly as an index for Short-Impending Prediction of Earthquakes. J. Earthquake Prediction Res. 8 (3), 241-255.

Harrison, R. G., Aplin, K. L., and Rycroft, M. J. (2010). Atmospheric Electricity Coupling between Earthquake Regions and the Ionosphere. J. Atmos. SolarTerrestrial Phys. 72 (5-6), 376-381. doi:10.1016/j.jastp.2009.12.004

Hattori, K., Serita, A., Gotoh, K., Yoshino, C., Harada, M., Isezaki, N., et al. (2004). ULF Geomagnetic Anomaly Associated with 2000 Izu Islands Earthquake Swarm, Japan. Phys. Chem. Earth, Parts A/B/C 29 (4-9), 425-435. doi:10.1016/j.pce.2003.11.014

Hayakawa, M., Asano, T., Rozhnoi, A., and Solovieva, M. (2018). "Very-low-and Low-Frequency Sounding of Ionospheric Perturbations and Possible Association with Earthquakes," in Pre-Earthquake Processes: A Multidisciplinary Approach To Earthquake Prediction Studies. Editors D. Ouzounov, S. Pulinets, K. Hattori, and P. Taylor (Hoboken: Wiley Online Library), 277-304.

Hayakawa, M. (1999). Atmospheric and Ionospheric Electromagnetic Phenomena Associated with Earthquakes. Tokyo: Terra Scientific Publishing Company.

Hayakawa, M. (2015). Earthquake Prediction with Radio Techniques. Singapore: Wiley Blackwell, 1-294. doi:10.1002/9781118770368

Hayakawa, M., Hobara, Y., Rozhnoi, A., Solovieva, M., Ohta, K., Izutsu, J., et al. (2013b). The Ionospheric Precursor to the 2011 March 11 Earthquake Based upon Observations Obtained from the japan-pacific Subionospheric VLF/LF Network. Terr. Atmos. Ocean. Sci. 24 (3), 393-408. doi:10.3319/ TAO.2012.12.14.01(AA10.3319/tao.2012.12.14.01(aa)
Hayakawa, M., Hobara, Y., Yasuda, Y., Yamaguchi, H., Ohta, K., Izutsu, J., et al. (2012). Possible Precursor to the March 11, 2011, Japan Earthquake: Ionospheric Perturbations as Seen by Subionospheric Very Low Frequency/ Low Frequency Propagation. Ann. Geophys. 55 (1), 95-99. doi:10.4401/ag-5357

Hayakawa, M., Ito, T., and Smirnova, N. (1999). Fractal Analysis of ULF Geomagnetic Data Associated with the Guam Earthquake on August 8, 1993. Geophys. Res. Lett. 26 (18), 2797-2800. doi:10.1029/1999GL005367

Hayakawa, M., Kasahara, Y., Nakamura, T., Hobara, Y., Rozhnoi, A., Solovieva, M., et al. (2011). Atmospheric Gravity Waves as a Possible Candidate for SeismoIonospheric Perturbations. Jae 31 (2), 129-140. doi:10.1541/jae.31.129

Hayakawa, M., Liu, J.-Y., Hattori, K., and Telesca, L. (2009). Electromagnetic Phenomena Associated with Earthquakes and Volcanoes. Phys. Chem. Earth 34 (6), 341-515. doi:10.1016/j.pce.2008.12.003

Hayakawa, M., and Molchanov, O. A. (2002). Seismo Electromagnetics: Lithosphere - Atmosphere - Ionosphere Coupling. Tokyo: TERRAPUB.

Hayakawa, M., Rozhnoi, A., Solovieva, M., Hobara, Y., Ohta, K., Schekotov, A., et al. (2013a). The Lower Ionospheric Perturbation as a Precursor to the 11 March 2011 Japan Earthquake. Geomatics, Nat. Hazards Risk 4 (3), 275-287. doi:10.1080/19475705.2012.751938

Hayakawa, M., Sue, Y., and Nakamura, T. (2009). The Effect of Earth Tides as Observed in Seismo-Electromagnetic Precursory Signals. Nat. Hazards Earth Sys. Sci. 9 (5), 1733-1741. doi:10.5194/nhess-9-1733-2009

Hayakawa, M., Yoshino, T., and Morgounov, V. A. (1993). On the Possible Influence of Seismic Activity on the Propagation of Magnetospheric Whistlers at Low Latitudes. Phys. Earth Planet. Interiors 77 (1-2), 97-108. doi:10.1016/0031-9201(93)90036-9

He, L., and Heki, K. (2017). Ionospheric Anomalies Immediately before M W 7.08.0 Earthquakes. J. Geophys. Res. Space Phys. 122 (8), 8659-8678. doi:10.1002/ 2017JA024012

Heki, K. (2011). Ionospheric Electron Enhancement Preceding the 2011 TohokuOki Earthquake. Geophys. Res. Lett. 38 (17), a-n. doi:10.1029/2011GL047908

Helman, D. S. (2020). Seismic Electric Signals (SES) and Earthquakes: A Review of an Updated VAN Method and Competing Hypotheses for SES Generation and Earthquake Triggering. Phys. Earth Planet. Interiors 302, 106484. doi:10.1016/ j.pepi.2020.106484

Ho, S.-P., Zhou, X., Shao, X., Zhang, B., Adhikari, L., Kireev, S., et al. (2020). Initial Assessment of the COSMIC-2/FORMOSAT-7 Neutral Atmosphere Data Quality in NESDIS/STAR Using In Situ and Satellite Data. Remote Sensing 12 (24), 4099. doi:10.3390/rs12244099

Ho, Y.-Y., Jhuang, H.-K., Lee, L.-C., and Liu, J.-Y. (2018). Ionospheric Density and Velocity Anomalies before $\mathrm{M} \geq 6.5$ Earthquakes Observed by DEMETER Satellite. J. Asian Earth Sci. 166, 210-222. doi:10.1016/j.jseaes.2018.07.022

Hobara, Y., and Parrot, M. (2005). Ionospheric Perturbations Linked to a Very Powerful Seismic Event. J. Atmos. Solar-Terrestrial Phys. 67 (7), 677-685. doi:10.1016/j.jastp.2005.02.006

Hough, S. (2020). The Great Quake Debate: The Crusader, the Skeptic, and the Rise of Modern Seismology. Seattle: University of Washington Press.

Huang, J., Lei, J., Lei, J., Li, S., Zeren, Z., Li, C., et al. (2018). The Electric Field Detector (EFD) Onboard the ZH-1 Satellite and First Observational Results. Earth Planet. Phys. 2 (6), 469-478. doi:10.26464/epp2018045

Ide, S., Beroza, G. C., Shelly, D. R., and Uchide, T. (2007). A Scaling Law for Slow Earthquakes. Nature 447 (7140), 76-79. doi:10.1038/nature05780

Ikuta, R., Hisada, T., Karakama, G., and Kuwano, O. (2020). Stochastic Evaluation of Pre-Earthquake TEC Enhancements. J. Geophys. Res. Space Phys. 125 (11), e2020JA027899. doi:10.1029/2020JA027899

Imamura, T., Ida, Y., Kasahara, Y., Nakamura, T., Hobara, Y., and Hayakawa, M. (2010). Fractal Analysis of Subionospheric LF Propagation Data and Consideration of the Lithosphere-Atmosphere-Ionosphere Coupling. Nat. Hazards Earth Syst. Sci. 10 (4), 901-906. doi:10.5194/nhess-10-901-2010

Inan, S., Akgül, T., Seyis, C., Saatçilar, R., Baykut, S., Ergintav, S., et al. (2008). Geochemical Monitoring in the Marmara Region (NW Turkey): A Search for Precursors of Seismic Activity. J. Geophys. Res. Solid Earth 113 (3), 3401. doi:10.1029/2007JB005206

Ingebritsen, S. E., and Manga, M. (2014). Hydrogeochemical Precursors. Nat. Geosci. 7 (10), 697-698. doi:10.1038/ngeo2261

Isaev, N. V., Sorokin, V. M., Chmyrev, V. M., Serebryakova, O. N., and Ovcharenko, O. Y. (2002). "Electric Field Enhancement in the Ionosphere 
above Tropical Storm Region," in Seismo Electromagnetics: LithosphereAtmosphere-Ionosphere Coupling (Tokyo: TERRAPUB), 313-315.

Jordan, T. H., Chen, Y. T., Gasparini, P., Madariaga, R., Main, I., Marzocchi, W., et al. (2011). Operational Earthquake Forecasting: State of Knowledge and Guidelines for Utilization. Ann. Geophys. 54 (4), 319-391. doi:10.4401/ag-5350

Kakinami, Y., Liu, J.-Y., Tsai, L.-C., and Oyama, K.-I. (2010). Ionospheric Electron Content Anomalies Detected by a FORMOSAT-3/COSMIC Empirical Model before and after the Wenchuan Earthquake. Int. J. Remote Sensing 31 (13), 3571-3578. doi:10.1080/01431161003727788

Kamiyama, M., Sugito, M., Kuse, M., Schekotov, A., and Hayakawa, M. (2016). On the Precursors to the 2011 Tohoku Earthquake: Crustal Movements and Electromagnetic Signatures. Geomatics, Nat. Hazards Risk 7 (2), 471-492. doi:10.1080/19475705.2014.937773

Kamogawa, M., and Kakinami, Y. (2013). Is an Ionospheric Electron Enhancement Preceding the 2011 Tohoku-Oki Earthquake a Precursor? J. Geophys. Res. Space Phys. 118 (4), 1751-1754. doi:10.1002/jgra.50118

Kanamori, H. (2003). Earthquake prediction: An overview. Int. Geophys. 81, 1205-1216. doi:10.1016/S0074-6142(03)80186-9

Kandalyan, R. A., and AlQuran, M. K. (2010). Ionosphere Scintillation and Earthquakes. Jordan J. Phys. 3 (2), 69-76.

Kang, C., and Liu, D. (2001). The Applicability of Satellite Remote Sensing in Monitoring Earthquake. Sci. Surv. Mapp. 26 (3), 46-48.

Kato, A., and Ben-Zion, Y. (2021). The Generation of Large Earthquakes. Nat. Rev. Earth Environ. 2 (1), 26-39. doi:10.1038/s43017-020-00108-w

Kim, V. P., and Hegai, V. V. (1999). "A Possible Presage of strong Earthquakes in the Night-Time Mid-latitude F2 Region Ionosphere," in Atmospheric and Ionospheric Electromagnetic Phenomena Associated with Earthquakes. Editor M. Hayakawa (Tokyo: Terrapub), 619.

Koike, K., Yoshinaga, T., Suetsugu, K., Kashiwaya, K., and Asaue, H. (2015). Controls on Radon Emission from Granite as Evidenced by Compression Testing to Failure. Geophys. J. Int. 203 (1), 428-436. doi:10.1093/gji/ggv290

Kondo, G. (1968). The Variation of the Atmospheric Electric Field at the Time of Earthquake. Mem. Kakioka Magnet. Observ. 12, 11-23.

Kopytenko, Y. A., Matiashvili, T. G., Voronov, P. M., Kopytenko, E. A., and Molchanov, O. A. (1993). Detection of Ultra-low-frequency Emissions Connected with the Spitak Earthquake and its Aftershock Activity, Based on Geomagnetic Pulsations Data at Dusheti and Vardzia Observatories. Phys. Earth Planet. Interiors 77 (1-2), 85-95. doi:10.1016/0031-9201(93)90035-8

Korepanov, V., Hayakawa, M., Yampolski, Y., and Lizunov, G. (2009). AGW as a Seismo-Ionospheric Coupling Responsible Agent. Phys. Chem. Earth, Parts A/B/C 34 (6-7), 485-495. doi:10.1016/j.pce.2008.07.014

Korsunova, L. P., and Khegai, V. V. (2008). Analysis of Seismoionospheric Disturbances at the Chain of Japanese Stations for Vertical Sounding of the Ionosphere. Geomagn. Aeron. 48 (3), 392-399. doi:10.1134/ S0016793208030134

Korsunova, L. P., and Khegai, V. V. (2006). Medium-term Ionospheric Precursors to strong Earthquakes. Int. J. Geomagn. Aeron. 6 (3), 1-8. doi:10.1029/ 2005gi000122

Kuo, C. L., Huba, J. D., Joyce, G., and Lee, L. C. (2011). Ionosphere Plasma Bubbles and Density Variations Induced by Pre-earthquake Rock Currents and Associated Surface Charges. J. Geophys. Res. 116 (10), a-n. doi:10.1029/ 2011JA016628

Kuo, C. L., Lee, L. C., and Huba, J. D. (2014). An Improved Coupling Model for the Lithosphere-Atmosphere-Ionosphere System. J. Geophys. Res. Space Phys. 119 (4), 3189-3205. doi:10.1002/2013JA019392

Kuznetsov, V. D., Bodnar, L., Garipov, G. K., Danilkin, V. A., Degtyar, V. G., Dokukin, V. S., et al. (2011). Orbital Monitoring of the Ionosphere and Abnormal Phenomena by the Small Vulkan-Compass-2 Satellite. Geomagn. Aeron. 51 (3), 329-341. doi:10.1134/S001679321103011X

Kuzuoka, S., and Mizuno, T. (2004). "Land Deformation Monitoring Using PSInSAR Technique," in International Symposium on Monitoring, Prediction and Mitigation of Disasters by Satellite Remote Sensing, MPMD-2004, Hyogo, 176-181.

Lagoutte, D., Brochot, J. Y., de Carvalho, D., Elie, F., Harivelo, F., Hobara, Y., et al. (2006). The DEMETER Science Mission Centre. Planet. Space Sci. 54 (5), 428-440. doi:10.1016/j.pss.2005.10.014

Larkina, V. I., Migulin, V. V., Molchanov, O. A., Kharkov, I. P., Inchin, A. S., and Schvetcova, V. B. (1989). Some Statistical Results on Very Low Frequency
Radiowave Emissions in the Upper Ionosphere over Earthquake Zones. Phys. Earth Planet. Interiors 57 (1-2), 100-109. doi:10.1016/0031-9201(89)90219-7

Larkina, V. I., Nalivayko, A. V., Gershenzon, N. I., Gokhberg, M. B., Liperovskiy, V. A., and Shalimov, S. L. (1983). Observations of VLF Emission, Related with Seismic Activity, on the Interkosmos-19 Satellite. Geomagnetism and Aeronomy $23(5), 684$.

Larkina, V., Migulin, V., Mogilevsky, M., Molchanov, O., Galperin, Y., Jorjio, N., et al. (1984). Earthquake Effects in the Ionosphere According to Intercosmos-19 and Aureol-3 Satellite Data. Results ARCAD-3 Project Recent Programmes Magnetospheric Ionospheric Phys. 685-699.

Li, M., Lu, J., Zhang, X., and Shen, X. (2019). Indications of Ground-Based Electromagnetic Observations to A Possible Lithosphere-AtmosphereIonosphere Electromagnetic Coupling before the 12 May 2008 Wenchuan MS 8.0 Earthquake. Atmosphere 10 (7), 355. doi:10.3390/atmos10070355

Li, M., and Parrot, M. (2012). "Real Time Analysis" of the Ion Density Measured by the Satellite DEMETER in Relation with the Seismic Activity. Nat. Hazards Earth Syst. Sci. 12 (9), 2957-2963. doi:10.5194/nhess-12-2957-2012

Li, M., Shen, X., Parrot, M., Zhang, X., Zhang, Y., Yu, C., et al. (2020). Primary Joint Statistical Seismic Influence on Ionospheric Parameters Recorded by the CSES and DEMETER Satellites. J. Geophys. Res. Space Phys. 125 (12), e2020JA028116. doi:10.1029/2020JA028116

Li, X. Q., Xu, Y. B., An, Z. H., Liang, X. H., Wang, P., Zhao, X. Y., et al. (2019). The High-Energy Particle Package Onboard CSES. Radiat. Detect. Technol. Methods 3 (3), 1-11. doi:10.1007/s41605-019-0101-7

Lin, C. Y., Lin, C. C. H., Liu, J. Y., Rajesh, P. K., Matsuo, T., Chou, M. Y., et al. (2020). The Early Results and Validation of FORMOSAT-7/COSMIC-2 Space Weather Products: Global Ionospheric Specification and Ne-Aided Abel Electron Density Profile. J. Geophys. Res. Space Phys. 125 (10), e2020JA028028. doi:10.1029/2020JA028028

Lin, J., Shen, X., Hu, L., Wang, L., and Zhu, F. (2018). CSES GNSS Ionospheric Inversion Technique, Validation and Error Analysis. Sci. China Technol. Sci. 61 (5), 669-677. doi:10.1007/s11431-018-9245-6

Liou, Y.-A., Kar, S. K., and Chang, L. (2010). Use of High-Resolution Formosat-2 Satellite Images for post-earthquake Disaster Assessment: A Study Following the 12 May 2008 Wenchuan Earthquake. Int. J. Remote Sensing 31 (13), 3355-3368. doi:10.1080/01431161003727655

Liperovsky, V. A., Meister, C.-V., Liperovskaya, E. V., and Bogdanov, V. V. (2008b). On the Generation of Electric Field and Infrared Radiation in Aerosol Clouds Due to Radon Emanation in the Atmosphere before Earthquakes. Nat. Hazards Earth Syst. Sci. 8 (5), 1199-1205. doi:10.5194/ nhess-8-1199-2008

Liperovsky, V. A., Pokhotelov, O. A., Meister, C.-V., and Liperovskaya, E. V. (2008a). Physical Models of Coupling in the Lithosphere-AtmosphereIonosphere System before Earthquakes. Geomagn. Aeron. 48 (6), 795-806. doi:10.1134/S0016793208060133

Liu, C., Guan, Y., Zheng, X., Zhang, A., Piero, D., and Sun, Y. (2019). The Technology of Space Plasma In-Situ Measurement on the China SeismoElectromagnetic Satellite. Sci. China Technol. Sci. 62 (5), 829-838. doi:10.1007/s11431-018-9345-8

Liu, D.-F., Peng, K.-Y., Liu, W.-H., Li, L.-Y., and Hou, J.-S. (1999). Thermal Omens before Earthquakes. Acta Seimol. Sin. 12 (6), 710-715. doi:10.1007/s11589-9990072-8

Liu, D. (2000). Anomalies Analyses on Satellite Remote Sensing OLR before Jiji Earthquake. Geo-Information Sci. 2 (1), 33-36.

Liu, J.-Y. G., Chang, F. Y., Lin, C.-Y., and Chen, Y.-I. (2020b). Ionospheric Earthquake Precursors and Space Weather Observed by FORMOSAT-7/ COSMIC-2. AGU Fall Meeting Abstracts.

Liu, J.-Y. G., Chang, F. Y., Lin, C. C. H., and Lin, C.-Y. (2020a). Advances in LowLatitude Ionosphere Observed by FORMOSAT-7/COSMIC-2. AGU Fall Meeting Abstracts, SA038-04.

Liu, J. Y., Chang, F. Y., Oyama, K. I., Kakinami, Y., Yeh, H. C., Yeh, T. L., et al. (2015). Topside Ionospheric Electron Temperature and Density along the Weddell Sea Latitude. J. Geophys. Res. Space Phys. 120 (1), 609-614. doi:10.1002/2014JA020227

Liu, J. Y., Chen, Y. I., Chen, C. H., Liu, C. Y., Chen, C. Y., Nishihashi, M., et al. (2009). Seismoionospheric GPS Total Electron Content Anomalies Observed before the 12 May 2008Mw7.9 Wenchuan Earthquake. J. Geophys. Res. 114 (4), a-n. doi:10.1029/2008JA013698 
Liu, J. Y., Chen, Y. I., Chuo, Y. J., and Chen, C. S. (2006). A Statistical Investigation of Preearthquake Ionospheric Anomaly. J. Geophys. Res. 111 (5), 5304. doi:10.1029/2005JA011333

Liu, Q., De Santis, A., Piscini, A., Cianchini, G., Ventura, G., and Shen, X. (2020c). Multi-Parametric Climatological Analysis Reveals the Involvement of Fluids in the Preparation Phase of the 2008 Ms 8.0 Wenchuan and 2013 Ms 7.0 Lushan Earthquakes. Remote Sensing 12 (10), 1663. doi:10.3390/rs12101663

Lizunov, G. V., Skorokhod, T. V., Skorokhod, T. V., and Korepanov, V. Y. (2020). Atmospheric Gravity Waves Among Other Physical Mechanisms of Seismic-Ionospheric Coupling. Kosm. Nauka Tehnol. 26 (3), 55-80. doi:10.15407/knit2020.03.055

Maekawa, S., Horie, T., Yamauchi, T., Sawaya, T., Ishikawa, M., Hayakawa, M., et al. (2006). A Statistical Study on the Effect of Earthquakes on the Ionosphere, Based on the Subionospheric LF Propagation Data in Japan. Ann. Geophys. 24 (8), 2219-2225. doi:10.5194/angeo-24-2219-2006

Marchetti, D., De Santis, A., D’Arcangelo, S., Poggio, F., Piscini, A., A. Campuzano, S., et al. (2019). Pre-earthquake Chain Processes Detected from Ground to Satellite Altitude in Preparation of the 2016-2017 Seismic Sequence in Central Italy. Remote Sensing Environ. 229, 93-99. doi:10.1016/j.rse.2019.04.033

Marchetti, D., De Santis, A., Shen, X., Campuzano, S. A., Perrone, L., Piscini, A., et al. (2020). Possible Lithosphere-Atmosphere-Ionosphere Coupling Effects Prior to the $2018 \mathrm{Mw}=7.5$ Indonesia Earthquake from Seismic, Atmospheric and Ionospheric Data. J. Asian Earth Sci. 188, 104097. doi:10.1016/ i.jseaes.2019.104097

Martinelli, G., Facca, G., Genzano, N., Gherardi, F., Lisi, M., Pierotti, L., et al. (2020). Earthquake-Related Signals in Central Italy Detected by Hydrogeochemical and Satellite Techniques. Front. Earth Sci. 8, 529. doi:10.3389/feart.2020.584716

Masci, F., Thomas, J. N., and Secan, J. A. (2017). On a Reported Effect in Ionospheric TEC Around the Time of the 6 April 2009 L'Aquila Earthquake. Nat. Hazards Earth Syst. Sci. 17 (9), 1461-1468. doi:10.5194/ nhess-17-1461-2017

Masci, F., Thomas, J. N., Villani, F., Secan, J. A., and Rivera, N. (2015). On the Onset of Ionospheric Precursors 40 Min before strong Earthquakes. J. Geophys. Res. Space Phys. 120 (2), 1383-1393. doi:10.1002/2014JA020822

Massonnet, D., Rossi, M., Carmona, C., Adragna, F., Peltzer, G., Feigl, K., et al. (1993). The Displacement Field of the Landers Earthquake Mapped by Radar Interferometry. Nature 364 (6433), 138-142. doi:10.1038/364138a0

Migulin, V., Larkina, V., Molchanov, O., Nalivaiko, A., Gokhberg, M., Liperovsky, V., et al. (1982). Detection of the Earthquake Effects on the VLF-ELF Noises in the Upper Ionosphere. Preprint IZMIRAN, Institute of Terrestrial Magnetism, Ionosphere and Radio Wave Propagation (IZMIRAN), USSR Academy of Sciences, Moscow 25 (390), 28.

Miyaki, K., Hayakawa, M., and Molchanov, O. A. (2002). "The Role of Gravity Waves in the Lithosphere-Ionosphere Coupling, as Revealed from the Subionospheric LF Propagation Data," in Seismo Electromagnetics: Lithosphere-Atmosphere-Ionosphere Coupling. Editors M. Hayakawa and O. A. Molchanov (Tokyo: TERRAPUB), 229-232.

Molchanov, O. A., Hayakawa, M., and Miyaki, K. (2001). VLF/LF Sounding of the Lower Ionosphere to Study the Role of Atmospheric Oscillations in the Lithosphere-Ionosphere Coupling. Adv. Polar Upper Atmos. Res. 15, 146-158.

Molchanov, O. A., and Hayakawa, M. (1998). Subionospheric VLF Signal Perturbations Possibly Related to Earthquakes. J. Geophys. Res. 103 (A8), 17489-17504. doi:10.1029/98ja00999

Molchanov, O. A., Mazhaeva, O. A., , et al.Molchanov, O. A., Mazhaeva, O. A., Golyavin, A. N., et al. (1993). Observation by the Intercosmos-24 Satellite of ELF-VLF Electromagnetic Emissions Associated with Earthquakes. AnGeo 11 (5), 431-440. Available at: https://ui.adsabs.harvard.edu/abs/1993AnGeo..11.. $431 \mathrm{M} / \mathrm{abstract}$.

Molchanov, O., Fedorov, E., Schekotov, A., Gordeev, E., Chebrov, V., Surkov, V., et al. (2004). Lithosphere-atmosphere-ionosphere Coupling as Governing Mechanism for Preseismic Short-Term Events in Atmosphere and Ionosphere. Nat. Hazards Earth Syst. Sci. 4 (5-6), 757-767. doi:10.5194/ nhess-4-757-2004

Moro, M., Saroli, M., Stramondo, S., Bignami, C., Albano, M., Falcucci, E., et al. (2017). New Insights into Earthquake Precursors from InSAR. Sci. Rep. 7 (1), 1-11. doi:10.1038/s41598-017-12058-3
Morozova, L. I. (1996). Features of Atmo-Lithmospheric Relationships during Periods of strong Asian Earthquakes. Fizika Zemli N. 5, 63-68.

Muto, F., Kasahara, Y., Hobara, Y., Hayakawa, M., Rozhnoi, A., Solovieva, M., et al. (2009). Further Study on the Role of Atmospheric Gravity Waves on the Seismo-Ionospheric Perturbations as Detected by Subionospheric VLF/LF Propagation. Nat. Hazards Earth Syst. Sci. 9 (4), 1111-1118. doi:10.5194/ nhess-9-1111-2009

Nakamura, T., Korepanov, V., Kasahara, Y., Hobara, Y., and Hayakawa, M. (2013). An Evidence on the Lithosphere-Ionosphere Coupling in Terms of Atmospheric Gravity Waves on the Basis of a Combined Analysis of Surface Pressure, Ionospheric Perturbations and Ground-Based ULF Variations. Jae 33 (1), 53-68. doi:10.1541/jae.33.53

Nakatani, M. (2020). Evaluation of Phenomena Preceding Earthquakes and Earthquake Predictability. J. Disaster Res. 15 (Issue 2), 112-143. doi:10.20965/jdr.2020.p0112

Nardò, S., Ascione, A., Mazzoli, S., Terranova, C., and Vilardo, G. (2020). PSInSAR Data Analysis: Pre-seismic Ground Deformation in the 2009 L'Aquila Earthquake Region. Bollettino di Geofisica Teorica ed Applicata 61 (1), 41-56. doi:10.4430/bgta0251

Natarajan, V., and Philipoff, P. (2018). Observation of Surface and Atmospheric Parameters Using "NOAA 18" Satellite: a Study on Earthquakes of Sumatra and Nicobar Is Regions for the Year $2014(\mathrm{M} \geq 6.0)$. Nat. Hazards 92 (2), 1097-1112. doi:10.1007/s11069-018-3242-y

Němec, F., Santolík, O., and Parrot, M. (2009). Decrease of Intensity of ELF/VLF Waves Observed in the Upper Ionosphere Close to Earthquakes: A Statistical Study. J. Geophys. Res. Space Phys. 114 (4), 4303. doi:10.1029/2008JA013972

Němec, F., Santolík, O., Parrot, M., and Rodger, C. J. (2010). Relationship between Median Intensities of Electromagnetic Emissions in the VLF Range and Lightning Activity. J. Geophys. Res. Space Phys. 115 (8), 8315. doi:10.1029/ 2010JA015296

Němek, F., Santolík, O., Parrot, M., and Berthelier, J. J. (2008). Spacecraft Observations of Electromagnetic Perturbations Connected with Seismic Activity. Geophys. Res. Lett. 35 (5), 5109. doi:10.1029/2007GL032517

Ohta, K., Izutsu, J., Schekotov, A., and Hayakawa, M. (2013). The ULF/ELF Electromagnetic Radiation before the 11 March 2011 Japanese Earthquake. Radio Sci. 48 (5), 589-596. doi:10.1002/rds.20064

Oikonomou, C., Haralambous, H., and Muslim, B. (2016). Investigation of Ionospheric TEC Precursors Related to the M7.8 Nepal and M8.3 Chile Earthquakes in 2015 Based on Spectral and Statistical Analysis. Nat. Hazards 83 (1), 97-116. doi:10.1007/s11069-016-2409-7

Olaiz, A. J., Muñoz-Martín, A., De Vicente, G., Vegas, R., and Cloetingh, S. (2009). European Continuous Active Tectonic Strain-Stress Map. Tectonophysics 474 (1-2), 33-40. doi:10.1016/j.tecto.2008.06.023

Omori, Y., Nagahama, H., Kawada, Y., Yasuoka, Y., Ishikawa, T., Tokonami, S., et al. (2009). Preseismic Alteration of Atmospheric Electrical Conditions Due to Anomalous Radon Emanation. Phys. Chem. Earth, Parts A/B/C 34 (6-7), 435-440. doi:10.1016/j.pce.2008.08.001

Ondoh, T. (2003). Anomalous Sporadic-E Layers Observed before M7.2 HyogoKen Nanbu Earthquake; Terrestrial Gas Emanation Model. Adv. Polar Upper Atmosphere Res. 17, 96-108. doi:10.15094/00006365

Ondoh, T., and Hayakawa, M. (2006). Synthetic Study of Precursory Phenomena of the M7.2 Hyogo-Ken Nanbu Earthquake. Phys. Chem. Earth, Parts A/B/C 31 (4-9), 378-388. doi:10.1016/j.pce.2006.02.017

Ondoh, T. (2009). Investigation of Precursory Phenomena in the Ionosphere, Atmosphere and Groundwater before Large Earthquakes of M>6.5. Adv. Space Res. 43 (2), 214-223. doi:10.1016/j.asr.2008.04.003

Ouzounov, D., and Freund, F. (2004). Mid-infrared Emission Prior to strong Earthquakes Analyzed by Remote Sensing Data. Adv. Space Res. 33 (3), 268-273. doi:10.1016/S0273-1177(03)00486-1

Ouzounov, D., Liu, D., Chunli, K., Cervone, G., Kafatos, M., and Taylor, P. (2007). Outgoing Long Wave Radiation Variability from IR Satellite Data Prior to Major Earthquakes. Tectonophysics 431 (1-4), 211-220. doi:10.1016/ j.tecto.2006.05.042

Ouzounov, D., Pulinets, S., Cervone, G., Singh, R., and Taylor, P. (2005). Atmospheric Processes in Reaction of Northern Sumatra Earthquake Sequence Dec 2004-Apr 2005. New Orleans: AGU Spring Meeting Abstracts.

Ouzounov, D., Pulinets, S., Hatori, K., and Taylor, P. (2018). Pre-Earthquake Processes: A Multidisciplinary Approach to Earthquake Prediction Studies. Hoboken: John 
Wiley \& Sons. Available at: https://www.wiley.com/en-us/Pre+Earthquake+Processes $\%$ $3 \mathrm{~A}+\mathrm{A}+$ Multidisciplinary+Approach + to+Earthquake+Prediction+Studies-p9781119156932

Ouzounov, D., Pulinets, S., Romanov, A., Romanov, A., Tsybulya, K., Davidenko, D., et al. (2011). Atmosphere-ionosphere Response to the M9 Tohoku Earthquake Revealed by Multi-Instrument Space-Borne and Ground Observations: Preliminary Results. Earthq. Sci. 24 (6), 557-564. doi:10.1007/ s11589-011-0817-z

Oyama, K.-I., Devi, M., Ryu, K., Chen, C. H., Liu, J. Y., Liu, H., et al. (2016). Modifications of the Ionosphere Prior to Large Earthquakes: Report from the Ionosphere Precursor Study Group. Geosci. Lett. 3 (1), 6. doi:10.1186/s40562016-0038-3

Park, C. G., and Dejnakarintra, M. (1973). Penetration of Thundercloud Electric fields into the Ionosphere and Magnetosphere: 1. Middle and Subauroral Latitudes. J. Geophys. Res. 78 (28), 6623-6633. doi:10.1029/ ja078i028p06623

Parrot, M. (1994). Statistical Study of ELF/VLF Emissions Recorded by a Low-Altitude Satellite during Seismic Events. J. Geophys. Res. Space Phys. 99 (12), 23339-23347. doi:10.1029/94JA02072

Parrot, M. (2018). "DEMETER Satellite and Detection of Earthquake Signals," in Natural Hazards: Earthquakes, Volcanoes, and Landslides. Editors R. Singh and D. Bartlett (New York: CRC Press), 115-138. doi:10.1201/9781315166841-6

Parrot, M., Lefeuvre, F., Parrot, M., and Lefeuvre, F. (1985). Correlation between GEOS VLF Emissions and Earthquakes. AnGeo 3, 737-747. https://ui.adsabs. harvard.edu/abs/1985AnGeo...3..737P/abstract.

Parrot, M., and Li, M. (2015). DEMETER Results Related to Seismic Activity. Radio Sci. Bull. 355, 18-25. https://www.ursi.org/content/RSB/RSB_355_2015_ 12.pdf.

Parrot, M., and Li, M. (2018). "Statistical Analysis of the Ionospheric Density Recorded by the DEMETER Satellite during Seismic Activity," in PreEarthquake Processes: A Multidisciplinary Approach to Earthquake Prediction Studies. Editors D. Ouzounov, S. Pulinets, K. Hattori, and P. Taylor (Hoboken: John Wiley \& Sons - American Geophysical Union (AGU)), 319-328. doi:10.1002/9781119156949.ch18

Parrot, M., and Mogilevsky, M. M. (1989). VLF Emissions Associated with Earthquakes and Observed in the Ionosphere and the Magnetosphere. Phys. Earth Planet. Interiors 57 (1-2), 86-99. doi:10.1016/0031-9201(89)90218-5

Parrot, M., and Pinçon, J.-L. (2020). Is There an Earthquake Weather? Ojer 09 (02), 69-82. doi:10.4236/ojer.2020.92005

Parrot, M. (2013). "Satellite Observations of Ionospheric Perturbations Related to Seismic Activity," in Earthquake Prediction Stud. Seismo Electromagnetics. Editor M. Hayakawa (Tokyo: TERRAPUB), 1-16.

Parrot, M. (2012). Statistical Analysis of Automatically Detected Ion Density Variations Recorded by DEMETER and Their Relation to Seismic Activity. Ann. Geophys. 55 (1), 149-155. doi:10.4401/ag-5270

Parrot, M. (2011). Statistical Analysis of the Ion Density Measured by the Satellite DEMETER in Relation with the Seismic Activity. Earthq. Sci. 24 (6), 513-521. doi:10.1007/s11589-011-0813-3

Parrot, M. (2002). The Micro-satellite DEMETER. J. Geodynamics 33 (4-5), 535-541. doi:10.1016/S0264-3707(02)00014-5

Parrot, M., Tramutoli, V., Liu, T. J. Y., Pulinets, S., Ouzounov, D., Genzano, N., et al. (2021). Atmospheric and Ionospheric Coupling Phenomena Associated with Large Earthquakes. Eur. Phys. J. Spec. Top. 230 (1), 197-225. doi:10.1140/ epjst/e2020-000251-3

Perrone, L., Korsunova, L. P., and Mikhailov, A. V. (2010). Ionospheric Precursors for Crustal Earthquakes in Italy. Ann. Geophys. 28 (4), 941-950. doi:10.5194/ angeo-28-941-2010

Phanikumar, D. V., Maurya, A. K., Kumar, K. N., Venkatesham, K., Singh, R., Sharma, S., et al. (2018). Anomalous Variations of VLF Sub-ionospheric Signal and Mesospheric Ozone Prior to 2015 Gorkha Nepal Earthquake. Sci. Rep. 8 (1), 1-9. doi:10.1038/s41598-018-27659-9

Picozza, P., Battiston, R., Ambrosi, G., Bartocci, S., Basara, L., Burger, W. J., et al. (2019). Scientific Goals and In-Orbit Performance of the High-Energy Particle Detector on Board the CSES. ApJS 243 (1), 16. doi:10.3847/1538-4365/ab276c

Pierce, E. T. (1976). Atmospheric Electricity and Earthquake Prediction. Geophys. Res. Lett. 3 (3), 185-188. doi:10.1029/GL003i003p00185

Piersanti, M., Materassi, M., Battiston, R., Carbone, V., Cicone, A., D’Angelo, G., et al. (2020). Magnetospheric-Ionospheric-Lithospheric Coupling Model. 1:
Observations during the 5 August 2018 Bayan Earthquake. Remote Sensing 12 (20), 3299. doi:10.3390/rs12203299

Píša, D., Němec, F., Santolík, O., Parrot, M., and Rycroft, M. (2013). Additional Attenuation of Natural VLF Electromagnetic Waves Observed by the DEMETER Spacecraft Resulting from Preseismic Activity. J. Geophys. Res. Space Phys. 118 (8), 5286-5295. doi:10.1002/jgra.50469

Písa, D., Parrot, M., and Santolík, O. (2011). Ionospheric Density Variations Recorded before the $2010 \mathrm{Mw} 8.8$ Earthquake in Chile. J. Geophys. Res. Space Phys. 116 (8), 8309. doi:10.1029/2011JA016611

Piscini, A., De Santis, A., Marchetti, D., and Cianchini, G. (2017). A MultiParametric Climatological Approach to Study the 2016 Amatrice-Norcia (Central Italy) Earthquake Preparatory Phase. Pure Appl. Geophys. 174 (10), 3673-3688. doi:10.1007/s00024-017-1597-8

Pritchard, M. E., Allen, R. M., Becker, T. W., Behn, M. D., Brodsky, E. E., Bürgmann, R., et al. (2020). "New Opportunities to Study Earthquake Precursors. Seismol. Res. Letters. 91, 2444-2447. doi:10.1785/0220200089

Pulinets, S. A., Ouzounov, D., Karelin, A. V., Boyarchuk, K. A., and Pokhmelnykh, L. A. (2006). The Physical Nature of thermal Anomalies Observed before strong Earthquakes. Phys. Chem. Earth, Parts A/B/C 31 (4-9), 143-153. doi:10.1016/ j.pce.2006.02.042

Pulinets, S., and Boyarchuk, K. (2005). "Ionospheric Precursors of Earthquakes," in Ionospheric Precursors of Earthquakes (Berlin: Springer), 1-315. doi:10.1007/ b137616

Pulinets, S. (2012). Low-latitude Atmosphere-Ionosphere Effects Initiated by strong Earthquakes Preparation Process. Int. J. Geophys. 2012, 1-14. doi:10.1155/2012/131842

Pulinets, S., Ouzounov, D., Karelin, A., and Davidenko, D. (2018). LithosphereAtmosphere-Ionosphere-Magnetosphere Coupling-A Concept for Preearthquake Signals Generation. Preâ€Earthquake Processes: A Multidisciplinary Approach to Earthquake Prediction Studies. Editors D. Ouzounov, S. Pulinets, K. Hattori, and P. Taylor (Hoboken: John Wiley \& Sons), 77-98. doi:10.1002/9781119156949.ch6

Pulinets, S., and Ouzounov, D. (2011). Lithosphere-Atmosphere-Ionosphere Coupling (LAIC) Model - an Unified Concept for Earthquake Precursors Validation. J. Asian Earth Sci. 41 (4-5), 371-382. doi:10.1016 j.jseaes.2010.03.005

Pulinets, S., and Ouzounov, D. (2018). The Possibility of Earthquake Forecasting: Learning from Nature. Bristol: IOP Publishing. doi:10.1088/978-0-7503-1248-6

Qin, K., Wu, L., De Santis, A., and Wang, H. (2011). Surface Latent Heat Flux Anomalies before the M S 7.1 New Zealand Earthquake 2010. Chin. Sci. Bull. 56, 3273-3280. doi:10.1007/s11434-011-4680-z

Qin, K., Wu, L. X., De Santis, A., and Cianchini, G. (2012). Preliminary Analysis of Surface Temperature Anomalies that Preceded the Two Major Emilia 2012 Earthquakes (Italy). Annal. Geophys. 55, 4. doi:10.4401/ag-6123

Qin, K., Zheng, S., Wu, L., and Wang, Y. (2021). Quasi-synchronous MultiParameter Anomalies before Wenchuan and Yushu Earthquakes in China. Eur. Phys. J. Spec. Top. 230 (1), 263-274. doi:10.1140/epjst/e2020-000253-3

Reddy, D. V., and Nagabhushanam, P. (2011). Groundwater Electrical Conductivity and Soil Radon Gas Monitoring for Earthquake Precursory Studies in Koyna, India. Appl. Geochem. 26 (5), 731-737. doi:10.1016/ j.apgeochem.2011.01.031

Rikitake, T. (1987). Earthquake Precursors in Japan: Precursor Time and Detectability. Tectonophysics 136 (3-4), 265-282. doi:10.1016/0040-1951(87) 90029-1

Rodger, C. J., Clilverd, M. A., and McCormick, R. J. (2003). Significance of Lightning-Generated Whistlers to Inner Radiation belt Electron Lifetimes. J. Geophys. Res. 108 (A12), 1462. doi:10.1029/2003JA009906

Rozhnoi, A., Solovieva, M., and Hayakawa, M. (2013). Earthquake Prediction Studies: Seismo Electromagnetics. Tokyo: TERRAPUB, 31-48.VLF/LF Signals Method for Searching of Electromagnetic Earthquake Precursors

Rulenko, O. P. (2000). Operative Precursors of Earthquakes in the Near-Ground Atmosphere Electricity. J. Volcanol. Seismol. 4, 57-68.

Ryu, K., Lee, E., Chae, J. S., Parrot, M., and Pulinets, S. (2014). Seismo-ionospheric Coupling Appearing as Equatorial Electron Density Enhancements Observed via DEMETER Electron Density Measurements. J. Geophys. Res. Space Phys. 119, 8524-8542. doi:10.1002/2014JA020284

Ryu, K., Oyama, K.-I., Bankov, L., Chen, C.-H., Devi, M., Liu, H., et al. (2016). Precursory Enhancement of EIA in the Morning Sector: Contribution from 
Mid-latitude Large Earthquakes in the north-east Asian Region. Adv. Space Res. 57 (1), 268-280. doi:10.1016/j.asr.2015.08.030

Sauvaud, J.-A., Maggiolo, R., Jacquey, C., Parrot, M., Berthelier, J.-J., Gamble, R. J., et al. (2008). Radiation belt Electron Precipitation Due to VLF Transmitters: Satellite Observations. Geophys. Res. Lett. 35 (9), 9101. doi:10.1029/ 2008GL033194

Schekotov, A., Fedorov, E., Hobara, Y., and Hayakawa, M. (2013). ULF Magnetic Field Depression as a Possible Precursor to the 2011/3.11 Japan Earthquake. Jae 33 (1), 41-51. doi:10.1541/jae.33.41

Scholz, C. H. (2019). "Earthquake Prediction and hazard Analysis," in The Mechanics of Earthquakes and Faulting. 3rd Edn. (Cambridge: Cambridge University Press), 337-380.

Scholz, C. H. (2002). The Mechanics of Earthquakes and Faulting. 2nd Edn. Cambridge: Cambridge University Press. doi:10.1017/cbo9780511818516

Serebryakova, O. N., Bilichenko, S. V., Chmyrev, V. M., Parrot, M., Rauch, J. L., Lefeuvre, F., et al. (1992). Electromagnetic ELF Radiation from Earthquake Regions as Observed by Low-Altitude Satellites. Geophys. Res. Lett. 19 (2), 91-94. doi:10.1029/91GL02775

Sgrigna, V., Buzzi, A., Conti, L., Picozza, P., Stagni, C., and Zilpimiani, D. (2007). Seismo-induced Effects in the Near-Earth Space: Combined Ground and Space Investigations as a Contribution to Earthquake Prediction. Tectonophysics 431 (1-4), 153-171. doi:10.1016/j.tecto.2006.05.034

Sgrigna, V., Buzzi, A., Conti, L., Picozza, P., Stagni, C., and Zilpimiani, D. (2008). The ESPERIA Satellite Project for Detecting Seismo-Associated Effects in the Topside Ionosphere. First Instrumental Tests in Space. Earth Planet. Sp 60 (5), 463-475. doi:10.1186/BF03352813

Sgrigna, V., Carota, L., Conti, L., Corsi, M., Galper, A. M., Koldashov, S. V., et al. (2005a). Correlations between Earthquakes and Anomalous Particle Bursts from SAMPEX/PET Satellite Observations. J. Atmos. Solar-Terrestrial Phys. 67 (15), 1448-1462. doi:10.1016/j.jastp.2005.07.008

Sgrigna, V., Console, R., Conti, L., Galper, A. M., Malvezzi, V., Parrot, M., et al. (2005b). "The ESPERIA Project: A mission to Investigate the Near-Earth Space," in Earth Observation with CHAMP: Results from Three Years in Orbit (Berlin: Springer-Verlag), 407-412. doi:10.1007/3-540-26800-6_65

Shapiro, S. A., Huenges, E., and Borm, G. (1997). Estimating the Crust Permeability from Fluid-Injection-Induced Seismic Emission at the KTB Site. Geophys. J. Int. 131 (2), F15-F18. doi:10.1111/j.1365246X.1997.tb01215.x

Sharma, G., Saikia, P., Walia, D., Banerjee, P., and Raju, P. L. N. (2021). TEC Anomalies Assessment for Earthquakes Precursors in North-Eastern India and Adjoining Region Using GPS Data Acquired during 2012-2018. Quat. Int. 575576 (576), 120-129. doi:10.1016/j.quaint.2020.07.009

Shen, X., Zhang, X., Yuan, S., Wang, L., Cao, J., Huang, J., et al. (2018). The StateOf-The-Art of the China Seismo-Electromagnetic Satellite mission. Sci. China Technol. Sci. 61 (5), 634-642. doi:10.1007/s11431-018-9242-0

Smirnova, N., Hayakawa, M., Gotoh, K., and Volobuev, D. (2001). Scaling Characteristics of ULF Geomagnetic fields at the Guam Seismoactive Area and Their Dynamics in Relation to the Earthquake. Nat. Hazards Earth Syst. Sci. 1 (3), 119-126. doi:10.5194/nhess-1-119-2001

Sorokin, V. M., and Chmyrev, V. M. (1999). "Modification of the Ionosphere by Seismic Related Electric Field," in Atmospheric and Ionospheric Electromagnetic Phenomena Associated with Earthquakes. Editor M. Hayakawa (Tokyo: Terra Sci. Publ. Co.), 805-818.

Sorokin, V. M., Chmyrev, V. M., and Yaschenko, A. K. (2001). Electrodynamic Model of the Lower Atmosphere and the Ionosphere Coupling. J. Atmos. SolarTerrestrial Phys. 63 (16), 1681-1691. doi:10.1016/s1364-6826(01)00047-5

Sorokin, V. M., Isaev, N. V., Yaschenko, A. K., Chmyrev, V. M., and Hayakawa, M. (2005). Strong DC Electric Field Formation in the Low Latitude Ionosphere over Typhoons. J. Atmos. Solar-Terrestrial Phys. 67 (14), 1269-1279. doi:10.1016/j.jastp.2005.06.014

Sotgiu, A., De Donato, C., Fornaro, C., Tassa, S., Scannavini, M., Iannaccio, D., et al. (2021). Control and Data Acquisition Software of the High-energy Particle Detector on Board the China Seismo-Electromagnetic Satellite Space mission. Softw. Pract. Exper 51 (6), 1459-1480. doi:10.1002/spe.2947

Tanimoto, T., Heki, K., and Artru-Lambin, J. (2015).Interaction of Solid Earth, Atmosphere, and Ionosphere. Treatise Geophys. 4. 421-443. doi:10.1016/B9780-444-53802-4.00083-X
Teng, T.-1., Sun, L.-f., and McRaney, J. K. (1981). Correlation of Groundwater Radon Anomalies with Earthquakes in the Greater Palmdale Bulge Area. Geophys. Res. Lett. 8 (5), 441-444. doi:10.1029/GL008i005p00441

Thomas, J. N., Love, J. J., Komjathy, A., Verkhoglyadova, O. P., Butala, M., and Rivera, N. (2012). On the Reported Ionospheric Precursor of the 1999 Hector Mine, California Earthquake. Geophys. Res. Lett. 39 (6), a-n. doi:10.1029/ 2012GL051022

Toledo-Redondo, S., Parrot, M., and Salinas, A. (2012). Variation of the First CutOff Frequency of the Earth-Ionosphere Waveguide Observed by DEMETER. J. Geophys. Res. 117 (4), a-n. doi:10.1029/2011JA017400

Tozzi, R., Masci, F., and Pezzopane, M. (2020). A Stress Test to Evaluate the Usefulness of Akaike Information Criterion in Short-Term Earthquake Prediction. Sci. Rep. 10 (1), 1-9. doi:10.1038/s41598-020-77834-0

Tramutoli, V., Aliano, C., Corrado, R., Filizzola, C., Genzano, N., Lisi, M., et al. (2013). On the Possible Origin of thermal Infrared Radiation (TIR) Anomalies in Earthquake-Prone Areas Observed Using Robust Satellite Techniques (RST). Chem. Geology. 339, 157-168. doi:10.1016/j.chemgeo.2012.10.042

Tramutoli, V., Corrado, R., Filizzola, C., Genzano, N., Lisi, M., and Pergola, N. (2015). From Visual Comparison to Robust Satellite Techniques: 30 Years of thermal Infrared Satellite Data Analyses for the Study of Earthquake Preparation Phases. Bollettino Di Geofisica Teorica e Applicata 56 (2), 167-202. Available at: http://www3.ogs.trieste.it/bgta/provapage.php?id_ articolo $=654$.

Tramutoli, V., Cuomo, V., Filizzola, C., Pergola, N., and Pietrapertosa, C. (2005). Assessing the Potential of thermal Infrared Satellite Surveys for Monitoring Seismically Active Areas: The Case of Kocaeli (İzmit) Earthquake, August 17, 1999. Remote Sensing Environ. 96 (3-4), 409-426. doi:10.1016/j.rse.2005.04.006

Tramutoli, V. (1998). Robust AVHRR Techniques (RAT) for Environmental Monitoring: Theory and Applications. Earth Surf. Remote Sensing 3496, 101-113.

Tramutoli, V. (2007). "Robust Satellite Techniques (RST) for Natural and Environmental Hazards Monitoring and Mitigation: Theory and Applications." in Proceedings of MultiTemp 2007 - 2007 International Workshop on the Analysis of Multi-Temporal Remote Sensing Images (Leuven: IEEE), 1-6. doi:10.1109/MULTITEMP.2007.4293057

Tronin, A. A. (2006). Remote Sensing and Earthquakes: A Review. Phys. Chem. Earth, Parts A/B/C 31 (4-9), 138-142. doi:10.1016/j.pce.2006.02.024

Uchida, N., and Bürgmann, R. (2021). A Decade of Lessons Learned from the 2011 Tohoku-Oki Earthquake. Rev. Geophys. 59 (2), e2020RG000713. doi:10.1029/ 2020rg000713

Venkatanathan, N., and Natyaganov, V. (2014). Outgoing Longwave Radiations as Pre-earthquake Signals: Preliminary Results of 24 September 2013 (M 7.7) Earthquake. Curr. Sci. 106 (9), 1291-1297. Available at: http://www.jstor.org/ stable/24102346.

Vershinin, E. F., Buzevich, A. V., Yumoto, K., Saita, K., and Tanaka, Y. (1999). "Correlations of Seismic Activity with Electromagnetic Emissions and Variations in Kamchatka Region," in Atmospheric and Ionospheric Electromagnetic Phenomena Associated with Earthquakes (Tokyo: Terra Scientific Publishing Company), 513-517.

Voronov, S. A. (1990). Increases in High Energy Charged Particle Fluxes Near the South Atlantic Magnetic Anomaly and the Seismicity of the Earth. Cosmic Res. $28,789-791$.

Wakita, H., Nakamura, Y., Notsu, K., Noguchi, M., and Asada, T. (1980). Radon Anomaly: A Possible Precursor of the 1978 Izu-Oshima-Kinkai Earthquake. Science 207 (4433), 882-883. doi:10.1126/science.207.4433.882

Wang, L., and Burgmann, R. (2019). Statistical Significance of Precursory Gravity Changes before the 2011 M W 9.0 Tohoku-Oki Earthquake. Geophys. Res. Lett. 46 (13), 7323-7332. doi:10.1029/2019GL082682

Warden, S., MacLean, L., Lemon, J., and Schneider, D. (2020). Statistical Analysis of Pre-earthquake Electromagnetic Anomalies in the ULF Range. J. Geophys. Res. Space Phys. 125 (10), e2020JA027955. doi:10.1029/2020JA027955

Weiyu, M., Xuedong, Z., Liu, J., Yao, Q., Zhou, B., Yue, C., et al. (2018). Influences of Multiple Layers of Air Temperature Differences on Tidal Forces and Tectonic Stress before, during and after the Jiujiang Earthquake. Remote Sensing Environ. 210, 159-165. doi:10.1016/j.rse.2018.03.003

Woith, H. (2015). Radon Earthquake Precursor: A Short Review. Eur. Phys. J. Spec. Top., 224, 611-627. doi:10.1140/epjst/e2015-02395-9 
Xiong, P., Long, C., Zhou, H., Battiston, R., Zhang, X., and Shen, X. (2020). Identification of Electromagnetic Pre-earthquake Perturbations from the DEMETER Data by Machine Learning. Remote Sensing 12 (21), 3643. doi: $10.3390 /$ rs 12213643

Xiong, P., Shen, X. H., Bi, Y. X., Kang, C. L., Chen, L. Z., Jing, F., et al. (2010). Study of Outgoing Longwave Radiation Anomalies Associated with Haiti Earthquake. Nat. Hazards Earth Syst. Sci. 10 (10), 2169-2178. doi:10.5194/nhess-10-21692010

Xiong, P., Tong, L., Zhang, K., Shen, X., Battiston, R., Ouzounov, D., et al. (2021). Towards Advancing the Earthquake Forecasting by Machine Learning of Satellite Data. Sci. Total Environ. 771, 145256. doi:10.1016/ j.scitotenv.2021.145256

Xiong, Z. (1992). Electromagnetic Modeling of 3-D Structures by the Method of System Iteration Using Integral Equations. Geophysc. 57 (12), 1556-1561. doi:10.1190/1.1443223

Xu, X., Sandwell, D. T., and Smith-Konter, B. (2020). Coseismic Displacements and Surface Fractures from sentinel-1 InSAR: 2019 Ridgecrest Earthquakes. Seismological Res. Lett. 91 (4), 1979-1985. doi:10.1785/0220190275

Xuhui, S., Zhima, Z., Jianping, H., Yanyan, Y., Shufan, Z., Rui, Y. A. N., et al. (2020). Current Status and Main Scientific Results of In-Flight CSES Mission. Chin. J. Space Sci. 40 (5), 662. doi:10.11728/cjss2020.05.662

Yan, R., Guan, Y., Guan, Y., Shen, X., Huang, J., Zhang, X., et al. (2018a). The Langmuir Probe Onboard CSES: Data Inversion Analysis Method and First Results. Earth Planet. Phys. 2 (6), 1-10. doi:10.26464/epp2018046

Yan, R., Parrot, M., and Pinçon, J.-L. (2017). Statistical Study on Variations of the Ionospheric Ion Density Observed by DEMETER and Related to Seismic Activities. J. Geophys. Res. Space Phys. 122 (12), 421-12,429. doi:10.1002/ 2017JA024623

Yan, R., Shen, X., Shen, X., Huang, J., Wang, Q., Chu, W., et al. (2018b). Examples of Unusual Ionospheric Observations by the CSES Prior to Earthquakes. Earth Planet. Phys. 2 (6), 515-526. doi:10.26464/epp2018050

Yang, S. S., Asano, T., and Hayakawa, M. (2019). Abnormal Gravity Wave Activity in the Stratosphere Prior to the 2016 Kumamoto Earthquakes. J. Geophys. Res. Space Phys. 124 (2), 1410-1425. doi:10.1029/2018JA026002

Zhai, D., Zhang, X., and Xiong, P. (2020). Detecting thermal Anomalies of Earthquake Process within Outgoing Longwave Radiation Using Time Series Forecasting Models. Ann. Geophys. 63 (5), 1-18. doi:10.4401/ag-8057

Zhang, K., Li, X., Zhao, H., Schiller, Q., Khoo, L. Y., Xiang, Z., et al. (2019). Cosmic Ray Albedo Neutron Decay (CRAND) as a Source of Inner Belt Electrons: Energy Spectrum Study. Geophys. Res. Lett. 46 (2), 544-552. doi:10.1029/ 2018GL080887

Zhang, X., Chen, H., Liu, J., Shen, X., Miao, Y., Du, X., et al. (2012). Ground-based and Satellite DC-ULF Electric Field Anomalies Around Wenchuan M8.0 Earthquake. Adv. Space Res. 50 (1), 85-95. doi:10.1016/j.asr.2012.03.018

Zhang, X., Shen, X., Zhao, S., Yao, L., Ouyang, X., and Qian, J. (2014). The Characteristics of Quasistatic Electric Field Perturbations Observed by DEMETER Satellite before Large Earthquakes. J. Asian Earth Sci. 79 (PA), 42-52. doi:10.1016/j.jseaes.2013.08.026
Zhang, X., Zeren, Z., Parrot, M., Battiston, R., Qian, J., and Shen, X. (2011). ULF/ ELF Ionospheric Electric Field and Plasma Perturbations Related to Chile Earthquakes. Adv. Space Res. 47 (6), 991-1000. doi:10.1016/j.asr.2010.11.001

Zhang, X., Zhao, S., Song, R., and Zhai, D. (2019). The Propagation Features of LF Radio Waves at Topside Ionosphere and Their Variations Possibly Related to Wenchuan Earthquake in 2008. Adv. Space Res. 63 (11), 3536-3544. doi:10.1016/j.asr.2019.02.008

Zhang, Y., Guo, X., Zhong, M., Shen, W., Li, W., and He, B. (2010). Wenchuan Earthquake: Brightness Temperature Changes from Satellite Infrared Information. Chin. Sci. Bull. 55 (18), 1917-1924. doi:10.1007/s11434-0103016-8

Zhang, Y., and Meng, Q. (2019). A Statistical Analysis of TIR Anomalies Extracted by RSTs in Relation to an Earthquake in the Sichuan Area Using MODIS LST Data. Nat. Hazards Earth Syst. Sci. 19 (3), 535-549. doi:10.5194/nhess-19-535-2019

Zhao, B., Wang, M., Yu, T., Wan, W., Lei, J., Liu, L., et al. (2008). Is an Unusual Large Enhancement of Ionospheric Electron Density Linked with the 2008 Great Wenchuan Earthquake? J. Geophys. Res. 113 (11), a-n. doi:10.1029/ 2008JA013613

Zhao, D., Qu, C., Shan, X., Gong, W., Zhang, Y., and Zhang, G. (2018). InSAR and GPS Derived Coseismic Deformation and Fault Model of the 2017 Ms7.0 Jiuzhaigou Earthquake in the Northeast Bayanhar Block. Tectonophysics 726, 86-99. doi:10.1016/j.tecto.2018.01.026

Zhu, K., Li, K., Fan, M., Chi, C., and Yu, Z. (2019). Precursor Analysis Associated with the Ecuador Earthquake Using Swarm A and C Satellite Magnetic Data Based on PCA. IEEE Access 7, 93927-93936. doi:10.1109/ ACCESS.2019.2928015

Zhu, K., Zheng, L., Yan, R., Shen, X., Zeren, Z., Xu, S., et al. (2021). Statistical Study on the Variations of Electron Density and Temperature Related to Seismic Activities Observed by CSES. Nat. Hazards Res. 2 (1). doi:10.1016/ j.nhres.2021.06.001

Zlotnicki, J., Li, F., and Parrot, M. (2013). Ionospheric Disturbances Recorded by DEMETER Satellite over Active Volcanoes: From August 2004 to December 2010. Int. J. Geophys. 2013, 1-17. doi:10.1155/2013/530865

Zlotnicki, J., Li, F., and Parrot, M. (2010). Signals Recorded by DEMETER Satellite over Active Volcanoes during the Period 2004 August-2007 December. Geophys. J. Int. 183 (3), 1332-1347. doi:10.1111/j.1365-246X.2010.04785.x

Conflict of Interest: The authors declare that the research was conducted in the absence of any commercial or financial relationships that could be construed as a potential conflict of interest.

Copyright (c) 2021 Picozza, Conti and Sotgiu. This is an open-access article distributed under the terms of the Creative Commons Attribution License (CC $B Y)$. The use, distribution or reproduction in other forums is permitted, provided the original author(s) and the copyright owner(s) are credited and that the original publication in this journal is cited, in accordance with accepted academic practice. No use, distribution or reproduction is permitted which does not comply with these terms. 